\title{
UNDERSTANDING TEACHER KNOWLEDGE OF THE USE OF ASSESSMENT FOR LEARNING IN THE CONTEXT OF HOMEWORK
}

A Dissertation
Presented to
the Faculty of the Graduate School
University of Missouri-Columbia
In Partial Fulfillment
Of the Requirement for the Degree
Doctor of Education
Dr. Robert Watson, Dissertation Supervisor
Daren Harris

May 2011 
The undersigned, appointed by the dean of the Graduate School, have examined the dissertation entitled

\section{UNDERSTANDING TEACHER KNOWLEDGE OF THE USE OF ASSESSMENT FOR LEARNING IN THE CONTEXT OF HOMEWORK}

presented by Daren Harris, a candidate for the degree of Doctor of Education, and hereby certify that, in their opinion, it is worthy of acceptance.

Dr. Robert Watson

Dr. Cynthia MacGregor

\section{Dr. Beth Hurst}

Dr. Gerald Moseman 


\section{Dedication}

Mom and Dad, thank you for always being by my side and making me the person I am today.

Jasmin and Aiden, daddy is done with his homework. I love you both.

To my family and friends, thank you so much for putting up with all the stuff associated with this personal quest. It was a long journey, and I thank you for your support.

Gail, thanks for pushing me to the end. You helped me more than you know. 


\section{Acknowledgements}

Without the support of many individuals this endeavor would have been difficult. This dissertation would not have been achievable without the help of my committee. I would like to thank Dr. Robert Watson for his friendship, help, and professional advice over the last several years. To Dr. Cindy MacGregor, thank you for helping me to find that qualitative was my true direction. To Dr. Moseman, thank you for your support of this project. To Dr. Hurst, thank you for my newfound appreciation for grammar, spacing, and the APA manual. To each of you, I say a very sincere thank you for helping me through the dissertation process. 


\section{TABLE OF CONTENTS}

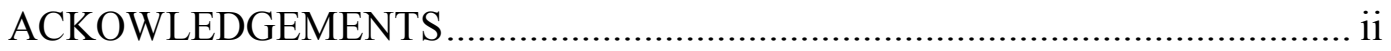

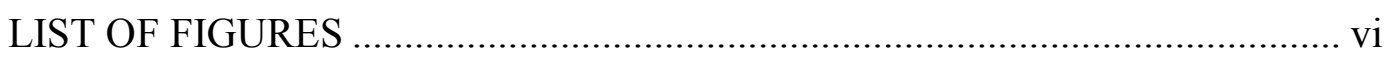

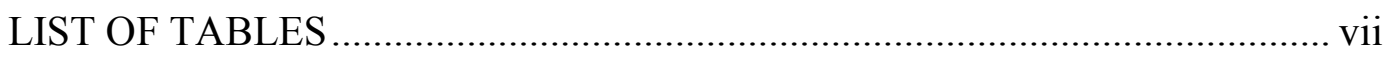

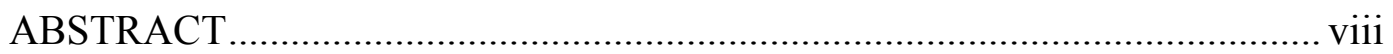

\section{Chapter}

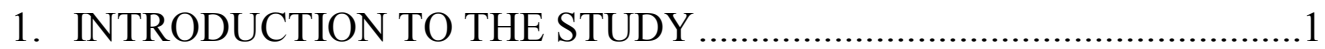

Conceptual Underpinnings....................................................................

Statement of the Problem...........................................................................17

Purpose of the Study ............................................................................19

Limitations, Assumptions, and Design Controls .......................................20

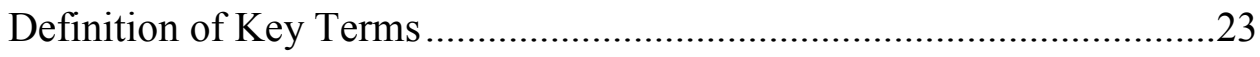

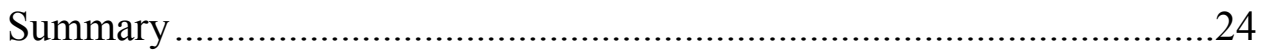

\section{REVIEW OF RELATED LITERATURE}

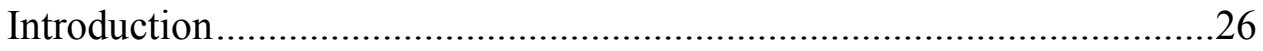

Assessment, Grading, and School Culture.................................................28

Assessment and Grading in Current Practice.................................................30

Assessment for Learning Conceptual Framework .......................................33

The Current Practice of Homework as Assessment....................................38

Homework as Assessment for Learning ....................................................43

Leadership and Change in Organizations ..................................................46

Organizational Learning and Assessment................................................54

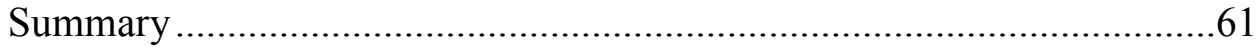




\section{RESEARCH DESIGN AND METHODOLGY}

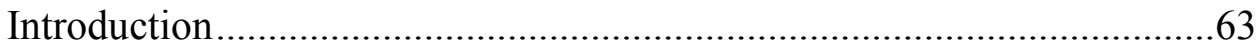

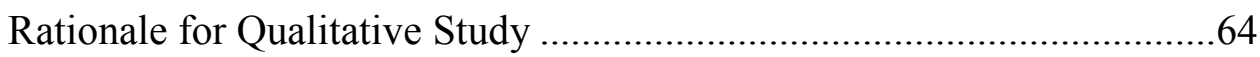

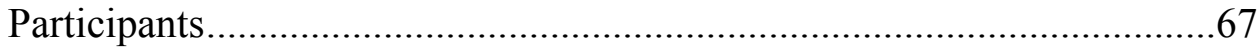

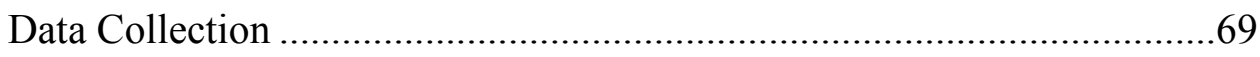

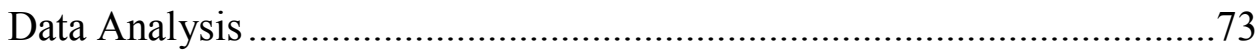

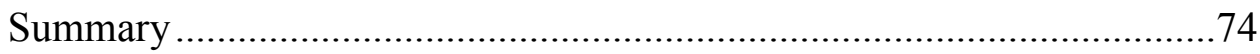

\section{DISCUSSION OF FINDINGS}

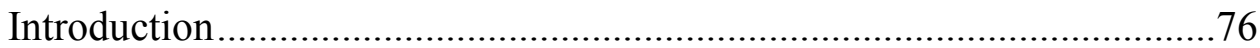

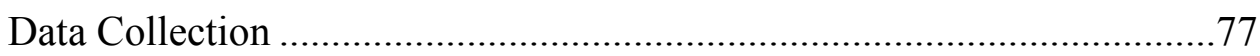

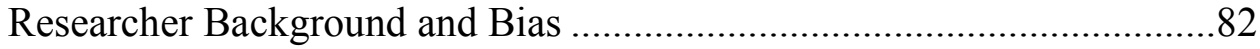

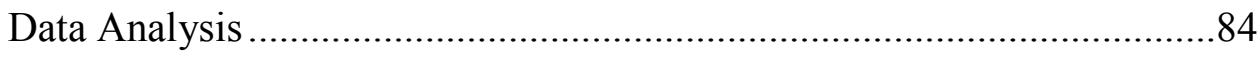

Teacher Perception of the Purpose of Homework .......................................85

Summary of Teacher Perceptions of the Purpose of Homework................99

The Uses of Homework as Part of Classroom Assessment Practice .........93

Summary of the Uses of Homework as Part of

Classroom Assessment Practice.................................................................97

Teacher Understanding of Homework as Formative Assessment ..............98

Summary of Teacher Understanding of Homework as

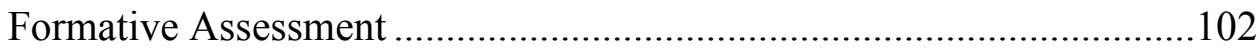

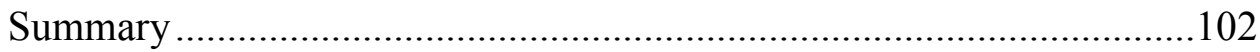

\section{CONCLUSION}

Introduction 106 


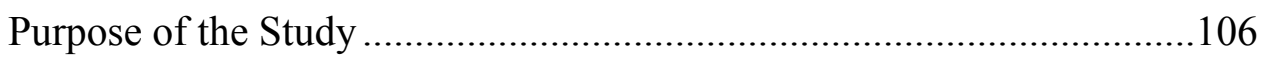

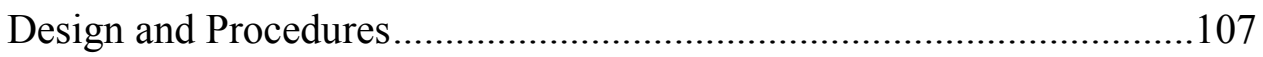

Conclusions Related to the Research Questions ..................................109

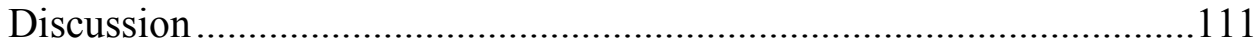

Implications for Future Practice......................................................114

Implications for Future Research ..................................................116

APPENDIX

A. FOCUS GROUP INTERVIEW PROTOCOL .....................................118

B. ONLINE OPEN-ENDED QUESTIONNAIRE .................................119

C. DOCUMENT ANALYSIS PROTOCOL ........................................120

D. INFORMED CONSENT ONLINE SURVEY ..................................121

E. INFORMED CONSENT FOCUS GROUP INTERVIEW ....................122

F. FOCUS GROUP INVITATION LETTER .....................................123

G. ONLINE SURVEY INVITATION ................................................124

H. TRANSCRIPTION VERIFICATION ............................................125

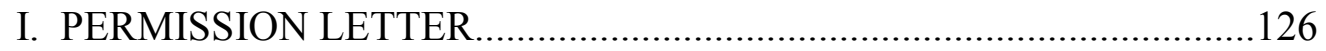

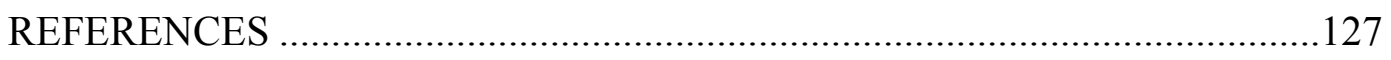

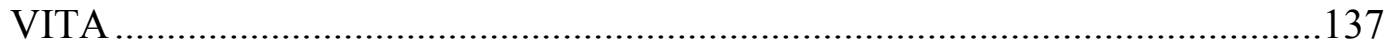




\section{LIST OF FIGURES}

1. Summary of Teacher Perception of the Purpose of Homework .................94

2. Summary of the Uses of Homework as Part of Classroom Assessment ....99

3. Summary of Teacher Understanding of Homework as a

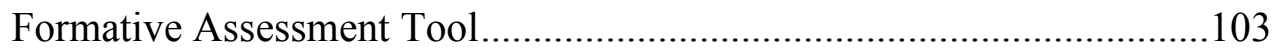

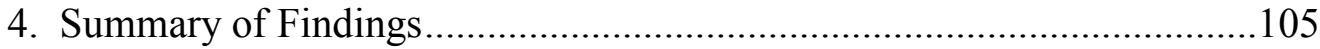




\section{LIST OF TABLES}

1. Identifying Codes and Demographics for Focus Group Participants ...81 


\title{
UNDERSTANDING TEACHER KNOWLEDGE OF THE USE OF ASSESSMENT FOR LEARNING IN THE CONTEXT OF HOMEWORK
}

\author{
Daren Harris
}

\author{
Dr. Robert Watson, Dissertation Supervisor
}

\begin{abstract}
The researcher conducted a qualitative study to develop a deeper understanding of teacher perceptions use, and understanding of homework as a formative assessment tool. The work of Black et al. (2004), Moss and Brookhart (2009), Stiggins et al. (2006) provided a lens to improve understanding of formative assessment. Cooper (2007), Kohn (2006), and Vatterott (2009) provided a lens to improve understanding of homework. Participants were teachers from three Midwestern high schools in one Midwestern state. Data were collected from focus group interviews, an online open-ended survey, and document analysis.
\end{abstract}

All segments of the participants identified three categories as related to perception, use, and understand homework as a formative assessment tool: teacher perception of the purpose of homework, the uses of homework as part of classroom assessment practice. The findings of this study have implications for teachers and administrators. The findings of this study include that teachers formulate their perception of homework on assumptions embedded in educational culture and teachers have a lack of understanding of homework as formative assessment. An implication for practice was educational leaders should be the leader of organizational learning. An implication for research was to find teacher attitudes before and after formative assessment training. 


\section{CHAPTER ONE}

\section{INTRODUCTION TO THE STUDY}

\section{Background}

Fullan (1993), in discussing change, stated:

The new problem of change is what would it take to make the educational system a learning organization-expert at dealing with change as a normal part of its work, not just in relation to the latest policy, but as a way of life. (p. 4) American public education has experienced many changes over the last few decades. A series of publications and reform measures attempted to provide a basis for a transformation in public schools. A Nation at Risk (National Commission on Excellence in Education, 1983) portrayed the American educational system as a national security risk. An ominous tone was set in the opening paragraphs language:

Our nation is at risk. Our once unchallenged preeminence in commerce, industry, science, and technological innovation is being overtaken by competitors throughout the world...The educational foundations of our society are presently being eroded by a rising tide of mediocrity that threatens our very future as a nation and as a people. (p. 5)

To address this scathing review, a number of movements to change the American educational system began to take place. The Excellence Movement in the 1980s and the Restructuring Movement in the 1990s attempted to bring reform to education, but with limited results (DuFour \& Eaker, 1998).

The Excellence Movement of the 1980s offered a direction for reform, but not a new direction. According to this movement, American schools needed to do more, not anything 
different. This top down approach delivered no appreciable results at the end of nearly a decade of work. From the failure of the Excellence Movement, the Restructuring Movement was developed in the 1990s. A bottom up movement emphasizing site based management and teacher empowerment, the Restructuring Movement led to peripheral changes rather than on core issues of teaching and learning (DuFour \& Eaker, 1998). Unfortunately, both movements have left classroom teaching practices untouched as the issues generated by each tend to focus outside the classroom and therefore have failed to meet the challenges American schools face.

In the American political arena, which has been the driving force behind the aforementioned movements, global economic competitiveness is the mantra which currently drives educational policy. Much of the pressures now exerted on American schools to improve can be directly traced to the emergence of the global economic system and the increased educational opportunities for people all over the world. Over the last fifty years, international organizations such as the United Nations Educational, Scientific, and Cultural Organization (UNESCO) and the Organization for Economic Cooperation and Development (OECD) have created a global education community poised to accelerate past the United States in the number of highly educated citizens (Resnick, 2006). The result of these organizations efforts has produced what has been labeled as the education-economic black box which has consolidated and diffused information throughout the developing world. The base of this education-economic black box is human capitol theory (Resnick, 2006).

Human capitol theory stems from classical and neoclassical economists Adam Smith, John Stuart Mill, and Alfred Marshall who regarded education as part of capitol and a national investment capable of paying enormous dividends (Resnick, 2006). Yorke and 
Knight (2006) noted, "The argument has been pressed that advanced economies could - and would - succeed when they made best use of their resources of knowledge, by creating and using plenty of human capitol" (p. 566). Across the globe, national and local governments implemented educational policy changes designed to foster environments in which education can be used as a primary source of economic viability. The increased complexity of economic globalization and competitiveness in various world markets placed the onus for an intelligent work force squarely on the shoulders of the world's educators. Further complicating this dilemma are the interests of the private sector who are beginning to assert their ideology that the development of human capitol is fundamental to economic success (Casey, 2006; Lagemann, 2007; Resnick, 2006; Yorke \& Knight, 2006).

To address the growing educational capabilities of the world, the United States government began to look at education as the impetus for a strong national approach to global competitiveness. Private business, politicians, and economists created inroads of influence within the American education community promoting human capital and a new knowledge based economy (Johnson \& Kasarda, 2008; Wilkinson, 2006). These inroads led to the creation of the American Competitiveness Initiative, No Child Left Behind, and increased pressures on education organizations to deliver knowledgeable graduates capable of contributing to economic success (Quevedo, 2007). Interestingly, there is a fallacy to the education-economic link often left out of the political discussion on school improvement.

It has been well noted over the last several decades, national economies have a great number of variables at play which negate the influence of education. For example, Japan led the world in test scores in the 1980s only to see their economy reach near collapse in the 1990s (Bracey, 2009). Similarly, Iceland scored high on a number of international 
assessments, but imploded economically in 2008-2009 due to high national debt. The reality is education does not create jobs, but rather produces educated people. India and China are now facing the prospect of an overeducated society which could result in a destabilization of their economies due to the lack of a parallel increase in job production. Singapore's students traditionally do well on tests; however, they lag behind United States students 10 or 20 years down the road. Individuals who decry the inability of United States education to produce test scores that rank high in the world order should take note of the Institute for Management Development (2009) and the World Economic Forum's (Porter \& Schwab, 2008) findings. Both organizations rate nations on their global competitiveness and each rank the United States as the most competitive nation in the world, especially in the area of innovation (Bracey, 2009).

In an interview, Singapore Minister of Education Tharman Shanmugaratnam cited creativity, curiosity, and a sense of adventure as examples of a few traits that set America apart from the rest of the world and tests simply do not measure these qualities (Zakaria, 2006). Unfortunately, recent national policy decisions have resulted in a mandated set of assessments designed to ensure equitable education opportunities for all students. Why is this unfortunate? As Sternberg (2006) observed, "The increasingly massive and far-reaching use of standardized tests is one of the most effective, if unintentional, vehicles this country has created for suppressing creativity" (p.47). None of the standardized tests currently used in American public schools are useful for comparing the quality of schools or teachers due to the diverse American population, high poverty rates, and a wide variety of pedagogical philosophies (Bracey, 2009). In discussing the educational measurement community, Stiggins (2002) noted, "For decades, our priorities have manifested the belief that our job is 
to discover ever more sophisticated and efficient ways of generating valid and reliable test scores" (p. 2). The result of the high stakes testing frenzy is a nation obsessed with standardized tests, which instead of leaving no child behind produced the opposite effect for many students.

The problem created by once a year tests is they provide no assistance to teachers in their quest to gather moment to moment information about student learning (Stiggins, 2002). More importantly, resources dedicated to the development of standardized tests whittle away at time and money that could be spent on providing educators with quality assessment training. An unfortunate result of this cycle is the perpetuation of a constant crisis in classroom, building, district, state, and national assessment systems with students suffering the consequences (Stiggins, 2002). So how do school leaders improve student learning and assessment in the face of this problem? By assisting teachers in the development of quality formative assessment which has a proven positive impact on reflective practice, teacher instructional methods, the assessments teachers use, and the students they teach in the classroom everyday.

The tests used for accountability today are not sensitive to instruction, which prevents their scores from being used for improvement in student achievement (Bracey, 2009). A quality assessment system does not rely on externally imposed measures, but rather on teacher development of classroom assessment tools which guide student learning. Focused, supported, and implemented classroom assessment systems which foster the relationship between teachers, school instructional leaders, and, more importantly, students, are proven to have a positive impact on student achievement. Unfortunately, few teachers and school administrators are prepared to face the challenge of creating quality classroom assessments 
because they have not been given the opportunity to learn how to do so (Stiggins, 2002). Moreover, there are no state or federal licensing requirements which verify competence in assessment (Stiggins, 2002). As a result, teacher preparation programs and school administrator preparation programs offer little in the area of providing competence in classroom assessments let alone the most important form of classroom assessment; assessment for learning.

Over the last three decades, educational research has helped to define two different forms of assessment; assessment of learning and assessment for learning. Standardized tests, whether they are international, national, state or local, or classroom tests, designed to measure or audit student attainment are assessments of learning. Stiggins (2006) stated, "Assessments of learning are those assessments that happen after learning is supposed to have occurred to determine if it did" (p. 2). In stark contrast to the international, national, state, district, and building assessments which attempt to measure student achievement in a single snapshot, assessment for learning happens while learning is still ongoing. Stiggins (2006) defined assessment for learning as:

These are the assessments that we conduct throughout teaching and learning to diagnose student needs, plan our next steps in instruction, provide students with the feedback they can use to improve the quality of their work, and help students see and feel in control of their journey to success. (p. 2)

Assessment for learning or formative assessment is an active and intentional learning process which partners teachers and students to continuously and systematically gather evidence of learning with the goal of improving student achievement (Moss \& Brookhart, 2009). A productive teacher-student partnership in the learning process, the development of collective 
inquiry, and conversations about learning become constants in a classroom where formative assessment is properly utilized. All these factors have a strong influence on student learning and teacher quality.

No other factor exerts greater influence on student achievement than teacher quality (Darling-Hammond 1999; Hanushek, Kain, O’Brien, \& Rivkin, 2005; Thompson \& Wiliam, 2007). Formative assessment affects teacher quality because it operates at the center of effective teaching (Black \& Wiliam, 1998; Elmore, 2004). Formative assessment engages teachers in a process where they learn about effective teaching by analyzing the effectiveness of their own instructional decisions (Moss \& Brookhart, 2009). Often teachers discuss their instruction in terms of what they "believe" is right or that a particular lesson "felt" like it went well. Such feelings and beliefs quite frequently are in contrast to the findings of educational research and the distinction is critical. Teacher beliefs and attitudes constitute not only their working assumptions about effective teaching, but also whether learning has occurred in the classroom.

For meaningful changes in teaching practices to occur, professional learning experiences that help teachers examine their working assumptions about how students learn and how good teaching supports learning need to be embedded as part school practice (Moss, 2002; Schreiber, Moss, \& Staab, 2007). In discussing the effect of formative assessment, Moss and Brookhart (2009) stated:

Formative assessment can have a transformational effect on teachers and teaching. In a very real way it flips a switch, shining a bright light on individual teaching decisions so that teachers can see clearly (and perhaps for the first time) the difference between the intent and the effect of their actions. (p. 10) 
Teachers begin to gather strong evidence of what students understand, what they need, and what does not work. Armed with this evidence, teachers can begin to see their effect on student learning through constant reflective practice.

When students are engaged in the learning process, learn how to learn, and understand how to adjust their learning the effects of formative assessment on students can be as dramatic as it is for teachers (Moss \& Brookhart, 2009). Through the teacher-student partnership students can begin to see the adjustments they need to make to improve their learning. Constantly gathering evidence about their learning and applying this information to strategies for success allows students to learn how to learn. Students begin to see themselves as autonomous, confident, capable learners with the ability to reach the learning goals of the subject matter. Moss and Brookhart (2009) stated, "This combination of learning factorsownership, autonomy, confidence, and capability-fortifies students with increased levels of resilience" (p. 12). Resilience is an important factor in maintaining or increasing student motivation for learning and avoiding the cycle of failure many students experience. When students judge themselves to be incapable of achieving and powerless to change their achievement level they become discouraged and give up (Ames, 1992; Boston, 2002; Vispoel \& Austin, 1995). This is a constant problem at the secondary level where many students have been experiencing failure and hopelessness for years.

The evidence is clear formative assessment works, and works because it has a direct impact on classroom practice. Unlike standardized tests which have little or no effect on the classroom, formative assessment presents the opportunity to raise the achievement standards of all students, but especially low achieving students. Black and Wiliam (1998) noted, “...it [formative assessment] helps low achievers more than any other students and so reduces the 
ranges of achievement while raising achievement for all” (p. 141). This can be directly attributed to the teacher-student relationship which is critical since both are the two most important players in the learning process. With such overwhelming evidence of the effectiveness of formative assessment the question becomes, how can it be integrated into classroom practice? School leaders focused on a commitment to change through dialogue, knowledge of research based practices teaching and learning practices, and the understanding of the importance of equitable educational opportunities for everyone within the school community are what is needed to resolve this critical issue.

\section{Conceptual Underpinnings}

Education in the public school setting was originally organized on the concepts and principles of the factory model (DuFour \& Eaker, 1998). Taylor (1911), in his book Principles of Scientific Management, argued “one best system” could be defined to complete any task or solve any problem an organization could encounter. Taylor promoted managers as the key problem solvers within the organization who could develop solutions to any problem. This top-down management model was readily embraced by early twentieth century educators who were enamored with the success of the industrial/factory model. As a result, the factory model of educating children became institutionalized in the public school setting. For a little over a century this model served the country well when only a minority of students graduated from high school and unskilled jobs were readily available (DuFour \& Eaker, 1998). These principles no longer serve students who are encountering an increasingly diverse and rapidly changing environment. DuFour and Eaker (1998) noted, "If schools are to be more effective they must break from the industrial model upon which they were created and embrace a new model that enables them to function as learning organizations" (p. 15). 
Covey (1996) stated "Only the organizations that have a passion for learning will have an enduring influence" (p. 149). To meet the educational goals of today, which call for all students to master rigorous content, learn to how to learn, pursue productive employment, and compete in a global economy, the factory model falls woefully short. More importantly, schools must embrace a new conceptual model and identifying this model is significant to school improvement (DuFour \& Eaker, 1998).

A preponderance of research over the last 30 years has given educators clear evidence on the effectiveness of developing a learning community. The change from a culture of isolation to one of collaboration and collective learning is exceedingly difficult. The hard work of change is critical if public education is to continue to be a viable educational option in the 21 st century. The demands of society to educate all students to high levels of learning and the increased complexity of a globalized economy create a sense of urgency for schools to transform themselves into learning communities.

The work of Nonaka (1991, 1994), Bruffee (1999), and Mezirow (2000) emphasized the importance of social interaction and communication as a central component of organizational learning. Morgan (2006) noted that "part of the challenge hinges on adopting an appropriate management philosophy that views and encourages the capacity of learning to learn as a key priority" (p. 97). School leaders need to create systems where discourse among the members of the organization coupled with an influx of knowledge becomes the method for understanding the importance of learning. If 21 st century educators and leaders are to uphold the moral and ethical obligation to educate all students, a change in the current status quo is essential. How can educational leaders break down the barriers to successful collaboration and ultimately foster a learning organization? Bruffee (1999) coined the term 
"reacculturation" as one method to begin the process of changing organizational culture into a collaborative environment. Focused conversations at the boundaries of two individual's communities of knowledge and the understanding that is a result of learning about each other defines reacculturation. It is through this understanding of the uniqueness of each individual's experience by which the change process toward the creation of a learning community can take root. Collaborative, conversational environments where educators rely on one another are a cultural shift for most schools.

A cultural shift toward a learning environment where interdependence between individuals is a norm can be difficult given the isolationist culture of most secondary school environments. Interdependence can alleviate the resistance to cultural change if leaders create systems of dialogue among diverse members of the organization. Bruffee (1999) affirms this notion stating:

This transitional process of translation, this willingness to learn the elements of new languages and gain new expertise, is the most important skill in the craft of interdependence. It is a willingness to become members of communities we have not belonged to before, by engaging in constructive conversation with others whose background and needs are similar to our own but also different. (p. 12)

Individuals who choose to accept the challenges of leadership need to be cognizant of the pitfalls and power of cultural change as a method to enhance learning. As Morgan (2006) noted in his metaphorical analysis of organizations as psychic prisons, "Culture gives us our world. And it traps us in that world!" (p. 211).

Persistent effort toward the creation of collaborative teams and constructive dialogue as a part of organizational culture is essential to learning. In order to foster learning and 
conversation, the fundamental structure of both the organization and meetings should be altered. Leaders need to create what Mezirow (2000) termed spaces where conversation can take place on issues and ideas essential to improving organizational effectiveness. A fundamental problem, however, is organizational members often view change with trepidation, and prefer stability. Bolman and Deal (2003) pointed out a flaw in this stance when they stated, "Organizations are reluctant to make major changes because a stable structure reduces confusion and uncertainty, maintains internal consistency, and protects the exiting equilibrium. The price of stability is a structure that grows increasingly misaligned with the environment" (p. 85). It is essential, however, for leaders to create time for organizational members to dialogue, in a structured manner, with each other on a consistent basis.

Constantly changing educational expectations have fostered a need for leaders who can develop follower skills and confidence in preparation for them to take more responsibility in an empowered organization (Yukl, 2006). Many leaders have turned to the tenets of transformational leadership as a guide to creating and maintaining learning communities within their organization. Transformational leadership can shape, alter, and elevate the motives, values, and goals of the followers through the vital teaching role of leadership (Burns, 1978). In describing transformational leadership Burns (1978) stated, The premise of this leadership is that, whatever the separate interests persons might hold, they are presently or potentially united in the pursuit of 'higher goals', the realization of which is tested by the achievement of significant change that represents the collective or pooled interests of leaders and followers. (pp. 425-426) 
Transformational leadership emphasizes how a collective commitment to organizational goals creates a capacity for change in the organization not limited to those in formal authority positions, but within all organizational members (Leithwood, Jantzi, \& Steinbach, 2000). Leithwood et al. (2000) stated, "power is attributed by organizational members to whomever is able to inspire their commitments to collective aspirations and the desire for personal and collective mastery of the capacities needed to accomplish such aspirations" (p. 9). The ability of any organizational member to have the power of influence within an organization is an important concept found within transformational leadership.

Leithwood and Duke (1999) developed the concept of transformational leadership, beyond those attributes mentioned previously, into seven dimensions: building school vision, establishing school goals, providing intellectual stimulation, offering individualized support, modeling best practices and important organizational values, demonstrating high performance expectations, creating a productive school culture, and developing structures to foster participation in school decisions.

Additionally, there are several behavior components which allow leaders to create this effort. Bass (1985) identified three types of behavior that transformational leaders use to inspire followers. Idealized influence is behavior that arouses strong emotions and identification with the leader. Intellectual stimulation is behavior that increases follower awareness of problems and encourages followers to view problems from various perspectives. Individualized consideration involves providing support, coaching, and encouragement to organizational members. Bass and Avolio (1990) added a fourth behavior, inspirational motivation, that includes communicating an appealing vision, using symbols to focus effort, and modeling desired behaviors. 
At no other time in educational history has the need for transformational leadership and critical discourse on teaching and learning been more prevalent than now. A change in the role of school administrators toward instructional leaders, a shift in organizational structure to a model which disperses leadership among its members, and the importance of dialogue as a tool for altering the school culture are the foundation for creating learning communities. Learning communities promote the ability of an organization to learn together in order to create a new knowledge which in turn alter the operation of the organization. The need to create learning organizations capable of altering classroom practice is more important than ever. Over the last decade, the transparency under which public schools operate has necessitated the need for change in the classroom environment. One area of classroom practice in desperate need of change is assessment.

The shift from teacher developed curriculum to standards based curriculum has necessitated the need for this change in assessment practice. Assessment practices of today fail to show any appreciable change from over 60 years ago. The obvious lack of assessment training in current university teacher preparation programs puts the process of changing current practice on the shoulders of school professional development programs. Compounding the issue is teacher professional development programs have traditionally lacked the training, support, and implementation mechanisms to truly bring about a change in practice (Stiggins, 2008). The professional development issue also extends to school leadership development programs which often are devoid of any preparation in understanding and supporting teachers in changing their current assessment practices. 
The success of a school in helping students achieve at high levels is directly correlated to the influence a principal or school leader has on the learning environment (Barth, 1990). To transform the current assessment practices utilized in the classroom educational leaders need to come to the position with knowledge and skills to support teachers through this change. A simple checklist of leader behaviors, great people skills or understanding the intricacies of organizational analysis is no longer sufficient for school leaders to be successful. While these are important, in order to change current assessment practices school leaders need a specific knowledge set to support teachers in their understanding of quality assessment (Chappius, 2005).

A framework specific to assessment for learning can allow school leaders to alter teacher practice and have a transformative affect on teacher beliefs of the role of assessment in the classroom. Chappius, Stiggins, Arter, and Chappius (2003) identified two characteristics critical to a framework of understanding assessment for school leaders. One, standards based reform has changed the requirements of schools from educating a percentage of students to educating all students to high standards. This shift from a teacher-centered curriculum to a standard public curriculum necessitates the need for day to day information on student learning not information from high stakes assessment or local short cycle common assessments (Chappius et al., 2003). Secondly, the reward of improved student learning in a standards based school which employs assessment for learning is undeniable. Gains in student achievement in schools where assessment for learning is embedded in every day practice are some of the largest ever reported (Black \& Wiliam, 1998).

A form of assessment often used by teachers is homework. Opinions on the need for homework, its use as an assessment tool, and its causation in relation to student achievement 
have been debated for the better part of a century. Vatterott (2009) noted, "The history of homework and surrounding attitudes is relevant because the roots of homework dogma developed and became entrenched over the last hundred years" (p. 3). A key word in that quote is entrenched and it is this very word which describes to school leaders the difficulty with dialogue on homework. Attitudes, assumptions, values, and beliefs all play a role in how homework is currently used in the classroom assessment arena. Unfortunately, like many traditions within schools there is no theoretical base to guide teachers in their use of homework.

In recent years, there has been research into homework as a tool to increase student achievement, but few which tackles the issue of how to use homework properly. Vatterott (2010) describes five traits of good homework: purpose, efficiency, ownership, competence, and aesthetic appeal. Chappius (2005), in discussing assessment for learning, identified three essential questions teachers should guide students to understand: where am I going, where am I now, and how can I close the gap. Vatterott's (2010) five traits of good homework and Chappius's (2004) three essential questions can serve as a foundation for teachers to begin to build quality homework practices that will enhance student achievement. However, the learning process will need to be spurred by school leaders who are competent in assessment, possess knowledge of teacher perceptions of assessment, and the ability to lead dialogue on transformational change.

The obvious lack of preparation in leadership programs in the specific area of homework compels school leaders to educate themselves either through reading or through professional development opportunities offered by experts in the field of assessment. School leaders have a moral obligation to seek out, gain competence, and apply the concepts of 
assessment for learning to help teachers understand how to more effectively use homework to improve student learning. In addition, school leaders committed to the principles of transformational leadership understand the importance of modeling best practice, educating teachers in critical areas of school improvement, and supporting teachers through change. More importantly, to build a learning community leaders need to have the knowledge to create and guide collaboration in a way which supports adult learning.

Substantive change in teacher practice can only come through professional development opportunities which not only introduce new practice, but probe for the understanding of current practice. Mezirow (2000) stated, "The justification for much of what we know and believe, our values, and our feelings, depends on the contextbiographical, historical, cultural-in which they are embedded" (p. 3). Exploration of these assumptions is the basis for new learning and a change in behavior. Mezirow (2000) gave insight to this idea when he noted, "Learning is understood as the process of using a prior interpretation to construe a new or revised interpretation of the meaning of one's experience as a guide to future action" (p. 5). Given Mezirow's thoughts, school leaders should probe current teacher understanding and knowledge of assessment then use the information gained as a component of school improvement. Without knowledge of teacher understanding and assumptions regarding homework a change in current homework and assessement practices will be exceedingly difficult for school leaders to implement.

\section{Statement of the Problem}

Assessment is an important part of the teaching-learning process often overlooked in the sea of reform measures designed to improve student achievement. A lack of rigorous preservice assessment training and inservice assessment training has resulted in an 
assessment crisis (Stiggins, 2008). Although there are many forms of assessment ranging from standardized test to classroom quizzes, the proper use of these assessments to impact student achievement is not commonly found in teacher practice. The change in mission for schools to educate all students in key standards has made it a necessity for educators to rethink assessment practice.

Stiggins (2008) stated, "As a result of this change in mission, assessment practices developed to separate the successful from the unsuccessful now must become practices that support the learning of all students, helping them master those required standards" (p. 2). Formative assessment or assessment for learning can play a major role in raising the achievement of all students when used as a part of classroom practice. Black and Wiliam (1998) noted, "Firm evidence shows that formative assessment is an essential component of classroom work and that its development can raise standards of achievement" (p. 139). A major part of classroom work is homework, but do homework assignments improve student achievement?

Research into the effectiveness of homework as a classroom assessment tool has led to conclusions that are inconsistent at best and contradictory as worst (Kohn, 2006: Trautwein \& Koller, 2003). Cooper, Robinson, and Patall (2006), leading researchers in homework, used several different statistical approaches to analyze the effect of homework on student achievement. Statistical analysis showed a correlation between high student achievement and the amount of homework completed (Vatterott, 2009). However, Cooper et al. (2006) have been unable to prove causation in relation to homework and student achievement. 
Despite these contradictory findings, homework is still a prevalent tool in classroom assessment and is used to audit student learning rather than a way to guide students toward a greater understanding of the learning process.

\section{Purpose of the Study}

The purpose of this study was to develop a further understanding of teacher knowledge of homework as a formative assessment tool (Vatterott, 2009), current classroom practice with regard to homework, and the perceived purpose of homework in the learning environment through a qualitative analysis of teacher assumptions about homework. The researcher elected to focus on teachers in the Midwestern United States. The research questions developed were utilized as a guide for the study. These questions are focused on homework practice as classroom assessment is a broad spectrum of various tools designed to measure or assist in student achievement.

\section{Research Questions}

Within the framework of this study, the following research questions were proposed:

1. What are teacher assumptions of the purpose of homework as a classroom assessment tool?

2. What are the uses of homework as a part of current classroom assessment practice?

3. What are current teacher understandings of homework as a formative assessment tool? 


\section{Limitations, Assumptions, and Design Controls}

\section{Limitations}

Teachers from selected school sites within the Midwestern United States were used for this study. The limited nature of the sample size makes it unwise to generalize the findings of this study to all public education settings. Variance in leadership and professional development practice from district to district has an impact on the practice within the classroom setting. An additional limitation in the study was researcher bias towards the responses of the subjects due to personal investment in the concept of formative assessment and a negative opinion toward homework as a tool to audit student learning. The document analysis process, which is part of the study, presented a limitation with regard to the inability to further investigate the rationale for the homework policies contained within its body. Three focus group interviews were conducted with individuals at different locations within the Midwest Region. Responses given during these interviews by the subjects may have been influenced by the presence of their peers. In a situation such as this groupthink can prevail when in actuality an individual may possess a different perspective than their peers. The data collection through open-ended survey questions provided data which might not be contained in the focus group interviews due to the nature of the instrument. Research subjects may be more inclined to share more personal views through an open-ended survey than when in a group setting where the threat of scrutiny by their peers is present.

\section{Assumptions}

The selection of secondary school teachers from a variety of content areas was purposefully done with the assumption there would be common viewpoints on homework. For this study, the researcher will employ a phenomenological strategy to inquiry. 
Phenomenological research relies on the identification of the essence of human experiences with relation to a phenomenon, as described by the participants in the study (Creswell, 2003). More importantly, the lived experiences of the participants are bracketed by the experiences of the researcher in order to gain a greater understanding of the phenomenon to be analyzed and the participants' perspective on said phenomenon (Moustakas, 1994). Although this study uses the phenomenological strategy, the researcher will be cognizant of ethnographic research strategy due to the nature of school culture. Ethnographic research aids in the recognition and analysis of culture sharing behaviors which are prevalent in all organizational settings (Creswell, 2003). The researcher found it suitable to assume the inclusive aspects of transformational leadership (Leithwood, Jantzi, \& Steinbach, 2000) as well as the transformative nature of the critical reflection components of adult learning theory (Mezirow, 2000).

\section{Design Controls}

Validity and reliability in research are keys if the results are to be utilized to either extend research or applied in the field. Merriam (1998) stated, "As research is concerned with producing valid and reliable knowledge in an ethical manner. Being able to trust research results is especially important to professionals in applied fields, such as education, in which practitioners intervene in people's lives" (p. 198). Cronbach (1975) emphasized a practical, action-oriented goal for researchers in the social sciences to make two primary contributions: "assess local events accurately, to improve short-run control" or "develop explanatory concepts, concepts that will help people use their heads" (p. 126).

Merriam (1998) noted, "One of the assumptions underlying qualitative research is that reality is holistic, multidimensional, and ever-changing; it is not a single, fixed, objective 
phenomenon waiting to be discovered, observed, and measured as in quantitative research" (p. 202). This means the researcher filters data through a lens situated in personal experience formed by the sociopolitical and historical moment (Creswell, 2003).

Merriam (1998) stated, "Internal validity deals with the question of how research findings match reality" (p. 201). An assumption of qualitative research is reality is ever changing, and holistic, not a fixed phenomena to be discovered. Qualitative research places the researcher in the role of the primary data collection instrument and because of this reality is a direct result of researcher observations (Merriam, 1998). Triangulation through the use of multiple sources of data can bolster reliability. Using document analysis, an open-ended survey, and focus group interviews with teachers will provide triangulation in this study. Member checking, taking interpretations back to the participants for their input on the viability of the results, will be another method to provide validity to the findings of the study.

Traditionally, reliability has been the extent to which the findings of one study can replicated (Merriam, 1998). This, however, is not possible within qualitative research since researchers seek to describe and explain the world through narrative description. As a researcher gains more experience as a human instrument for data collection the reliability of findings increase (Merriam, 1998). To further increase reliability, the researcher should explain the assumptions of the study, provide for triangulation, explain key decision during the research, and detail the coding system used to collate the data.

Qualitative research places the researcher within the study and because of this position reflexivity is an important component of the design. The inherent bias a researcher brings into the study requires critical examination and a method to emancipate the study from these biases. Coghlan and Brannick (2005) defined epistemic reflexivity as an approach that 
looks at exposing interests and enabling emancipations through self-reflexivity. Furthermore, epistemic reflexivity is grounded in democratic principles and a commitment to change by engagement in reflective practice.

\section{Definition of Key Terms}

The following terms are relevant to this study are defined and will assist in understanding key concepts contained within this study.

Assessment for Learning (Formative Assessment). An active and intentional learning process that partners the teacher and the students to continuously and systematically gather evidence of learning with the express goal of improving student achievement (Moss \& Brookhart, 2009, p. 6).

Assessment of Learning. Are those assessments that happen after learning is supposed to have occurred to determine if it did (Stiggins, Arter, Chappius, \& Chappius, 2006, p. 31).

Classroom assessments. Measurements tools designed to measure or assist in improving student learning which can include: exams or compositions, quizzes, reports or projects, student portfolios, oral presentations, homework, class participation, laboratory projects, student notebooks or journals, punctuality of assignments, effort, attendance, behavior, and progress made (Guskey \& Bailey, 2001).

Common assessment-Is a term used to describe teacher made assessments designed to measure student understanding of essential curricular concepts so adjustments in instruction can occur in the future (DuFour \& Eaker, 1998).

Criterion referenced assessment. Test results that allow educators to reference a student's score back to a clearly defined skill or body of knowledge (Popham, 2003). 
Descriptive Feedback. A teacher's response to student work with the intention of furthering learning (Moss \& Brookhart, 2009).

Homework. Classroom assessment designed to extend learning time beyond the formal school day (Vatterott, 2009).

Learning target. Achievement standards students are expected to master (Stiggins et al., 2006).

Metacognition. Students' awareness about their own thinking and their use of this self-awareness to regulate their thinking (Moss \& Brookhart, 2009).

Norm referenced assessment. Test results that allow a student's schore to be reference back to the scores of a norm group (Popham, 2003).

Self-efficacy. A learner's belief in their ability to succeed in a particular situation (Moss \& Brookhart, 2009).

\section{Summary}

The information in Chapter One provided the purpose, justification, and important definitions and key terms and concepts of the study. In summary, the purpose of this study was to understand the perceptions teachers and school leaders with regards to the role assessment, grading, and homework has in student learning. The current literature on leadership, the role of leadership in the change process, and classroom assessments future role in student learning provided the background for this study. There is an extensive body of research on teacher practices in the areas of classroom assessment, grading, and homework practice. However, this study is designed to further analyze teacher perception of the role of homework, their understanding of assessment for learning, and their professional development experience as it pertains to assessment for learning. 
Chapter Two consists of a review of the relevant literature regarding grading practices, motivation theory, retention theory, assessment, and homework practice. A review of the extensive research on the aforementioned concepts as well as Mezirow's compilation on the theoretical concept of adult learning and research on transformational leadership theory is also presented.

Research methodology intended to be used in the study is presented in Chapter Three, along with the rationale for the selection of the institutions to be studied, a description of research participants, and method of data collection and analysis will be discussed. 


\section{CHAPTER TWO}

\section{REVIEW OF RELATED LITERATURE}

\section{Introduction}

In his 1854 classic Walden, Thoreau wrote:

It is never too late to give up our prejudices. No way of thinking or doing, however ancient, can be trusted without proof. What every body echoes or in silence passes by as true to-day may turn out to be falsehood to-morrow, mere smoke of opinion, which some had trusted for a cloud that would sprinkle fertilizing rain on their fields. (p. 11) Organizations across the globe are captured in the very pattern of thinking that Thoreau touched upon, and, as a result, find themselves in a struggle for existence. Perhaps more than any other, educational organizations cling to current practice in many areas and the reluctance to challenge the status quo has resulted in problems for their most valuable asset, students. Educational leaders of the $21^{\text {st }}$ century need to be able to understand and utilize multiple lenses to analyze the current status of all facets of their organization. Authors such as Morgan (2006) and Bolman and Deal (2003) have provided metaphors that allow leaders to see the current reality of their organization and why change is so difficult for its members.

In their book Reframing Organizations Bolman and Deal (2003) created the phrase "the curse of cluelessness" (p. 6) to describe the inability of organizations to see reality. Frequently the brightest individuals assume managerial positions in some of the world's greatest companies only to perform in a manner that hurts their organizations. Whether it is arrogance, ego, or simply not being able to see a different way, poor decisions create immense dilemmas. Bolman and Deal (2003) noted:

The real source of cluelessness is not personality or IQ. It is how we think and 
make sense of the world around us. Regardless of intellectual wattage, we're out to lunch if we use the wrong ideas for the situation at hand. (p. 6)

Organizations often have elements in place which lend themselves to creating the cluelessness mentioned by Bolman and Deal. Traditions, politics, policies, procedures, and human needs all play a role in blinding organizational members from understanding the vital role change can play.

Assessment practices play an essential role in the educational setting from kindergarten to the university level. Currently, the assessment practices used by teachers are largely based on traditional methods and not what research states as best practice (Brookhart, 2008; Guskey \& Bailey, 2001; Stiggins, 2004). The transparency in which schools operate under and the demand to educate all students to high levels make the need for quality assessments based on sound research, not tradition or opinion, even more imperative (Stiggins, 2008). More importantly, the shift from norm referenced assessments designed to sort and select to criterion referenced assessments designed to measure student attainment of standards has been pressed to the forefront (Stiggins, 2008).

A historical review of assessment practices in American education allows a greater understanding of the current state of assessment and how best to begin to alter current assessment practices. Changing long standing traditions or opinions upon which teachers base a major portion of their professional stability will be difficult. In order to facilitate change in assessment practices an examination of educational organizations, current theory on leadership, and current theory on adult learning will provide insight on methods by which a shift to research based assessment practices can be achieved. Finally, a thorough analysis of 
research based concepts in the area of assessment and grading will be examined to provide implications for future teacher practices in this critical area of education.

\section{Assessment, Grading and School Culture}

The struggle over how to properly assess student learning is one that has been in existence since the inception of large scale organized public education. Guskey and Bailey (2001) reported finding over 4,000 books, essays, articles, and research studies related to the area of assessment and grade reporting dating back as far as 1933. In a series of metaanalysis, Moss and Brookhart (2009) reported finding the basis for current assessment and grading practices embedded in the needs of $20^{\text {th }}$ century society to sort students into two categories, the winners and the losers. However, increasing political and societal pressures have forced educators to begin to rethink many of their culturally embedded instructional practices and to place more focus on research based instructional methodology. As Guskey and Bailey (2001) stated, “Change is never easy. It's especially difficult in education because so much current practice is based on tradition rather than compelling evidence of effectiveness" (p. 9). In order to effectively change an organization and its practices, a close examination of the traditions found within the culture of an organization is imperative.

Traditions, symbols, and rituals are the guiding cultural assumptions on which an organization bases many actions. Schein (1992), defined culture as:

A pattern of shared basic assumptions that a group learned as it solved its problems of external adaptation and integration, that has worked well enough to be considered valid and therefore to be taught to new members as the correct way to perceive, think, and feel in relation to those problems. (p.12) 
Deeply embedded within educational culture are methods by which students are assessed on their level of knowledge and how these assessments create a view of student achievement. For many years assessment has not only been a tool to measure student achievement, but also has been a tool to sort and select students. Current assessment practice has been a direct reflection of the cultural identity the United States has developed in the post World War II global society. Morgan (2006), in his analysis of organizational cultures across the globe, noted "...the United States stands supreme in the extent to which a concern for winning and direct reward for appropriate behavior have established themselves important features of the culture and corporate life" (p. 124). This cultural identity unique to the United States has fostered a powerful pressure that is exerted on those in both the corporate and educational fields.

"Organizations are mini-societies that have their own distinctive patterns of culture and subculture" (Morgan, 2006). This quote applied to educational organizations can assist in a greater understanding of how assessment has evolved over time to the state it is now in most American schools. Large scale, standardized, norm referenced assessments garner more attention because of the well funded, high profile nature of the research conducted on them; however, classroom assessment has a more far reaching effect. As Brookhart (2003) noted, "Understanding the dynamics of classroom assessment is essential for improving education or even for understanding the current state of learning in classrooms" (p. 28). The strong tradition of grading and classroom assessment coupled with little required training on either has created an assessment crisis in the education field. 


\section{Assessment and Grading in Current Practice}

Grades are not essential for learning, yet they dominate the culture of high schools (O'Connor, 2009). A majority of current grading practices are deeply embedded in the beliefs and experiences of teachers. The lack of effective preservice or inservice professional development programs in the area of grading only helps entrench grading practices in tradition. In the most recent comprehensive survey on high school grading policies by the College Board (1998) found:

a large majority of schools use a traditional grading system of A-F or numeric grades (91\%), use the same grading system for all academic courses (92.2\%), report GPA (90.1\%), and calculate a high school class rank (81.3\%)....Approximately $8 \%$ of schools report using nontraditional grading system and only $1 \%$ of schools do not assign grades. (p. 2)

The only change since this survey is fewer schools are reporting class rank (O'Connor, 2009).

O'Connor (2009) stated, "It is essential to be clear about the primary purpose of grades, which is to communicate students' achievement of learning goals" (p. 2). The secondary purpose is to provide teachers with information for instructional planning and providing teachers, students, parents, and administrators with information for placement of students (Brookhart, 2004). In an ideal world grades would provide teachers and students with accurate feedback about student progress toward established learning goals. However, a problematic aspect of grading is the many different factors teachers can use to arrive at a grade. 
A great number of teachers combine behavior, participation, and responsibility along with achievement results to create a grade. Guskey and Bailey (2001) identified what teachers typically use as sources of grading: exams or compositions, quizzes, reports or projects, student portfolios, oral presentations, homework, class participation, laboratory projects, student notebooks or journals, punctuality of assignments, effort, attendance, behavior, and progress made. A majority of teachers use behavior because they feel it demonstrates what they value and will increase student motivation for students who exhibit good behavior (O’Connor, 2009). Gathercoal (2004) stated, “...due to the excessive entanglement between achievement and behavior, achievement grades are often misinterpreted" (p. 153). Interestingly, Reeves (2008) found, "When schools improve grading policies-for example by disconnecting grades from behavior-student achievement increases and behavior improves dramatically" (p. 90).

There is strong evidence to show that grades have a profound influence on students' attitudes, behavior, and motivation to learn (Brookhart, 2004; McMillan, 2001). High achieving students work hard in rigorous courses to attain good grades for college entrance while low achieving students often use grades as a factor in their decision to leave school (Guskey, 2004a). Grading practices that combine multiple factors send students the message that compliance is more important than learning. Students who are not compliant with the structure established by the grading practices found inside the classroom often find themselves left out of the learning process.

When classroom policies use grades as a tool for punishment the affect on student motivation is detrimental. Guskey (2009), observed, “...no studies support the use of low grades as punishment. Instead of prompting greater effort, low grades more often cause 
students to withdraw from learning" (p. 14). Despite empirical evidence to the contrary teachers continue to use grading practices as an extrinsic motivator to improve student performance. Extrinsic motivation certainly has a place in classroom practice, but consistently using grades in a reward-punishment system has a downside. Extrinsic motivators require teachers to use rewards, in the form of bonus points, or punishments, in the form of lower grades, to motivate students.

A grading system based on extrinsic rewards can, over time, have a counterproductive affect on intrinsic motivation. In such a system, students who perform better on assessments get the most rewards while students who perform the worst get the least rewards (Moss \& Brookhart, 2009). For students who cannot meet the requirements, this type of external control weakens their motivation to learn, undercuts their performance, and leaves them demoralized (Deci, Koestner, \& Ryan, 1999). Similarly, Stiggins et al. (2006) stated intrinsic motivation can be diminished by coercion, intimidation, punishments or rewards linked to grades, infrequent or vague feedback, limited personal control, and responsibility without authority. Most schools promote themselves as environments that hope to foster lifelong learning; however, the use of current grading practices has been shown to have quite the opposite effect.

Dweck (2007) stated, "It matters greatly what students believe about their intelligence" (p. 6). Students who believe intelligence is innate and those who believe their achievement can get better through effort and learning present opposite sides of the motivation spectrum. Recent studies show teaching students a growth mindset results in increased motivation, better grades, and higher achievement results (Dweck, 2007). Motivation is enhanced when students are provided accurate information about achievement, 
have clear learning goals, and study in an environment that supports learning by not including all classroom assessment in grading and by being positive and supportive (O’Connor, 2009).

One form of classroom assessment often graded and improperly used as an extrinsic motivator is homework. Homework's misuse stems from the misinterpretation on the part of teachers as to the role homework should and could play in promoting student learning. Currently used as a form of extrinsic motivation due to the classroom or school policies which blend behavior with learning, homework has become one method of teaching responsibility. The culture of school assessment has created the misconception of homework as a tool to control student behavior instead of its potential to foster self directed behavior which increases student learning (Vatterott, 2009).

Assessment for Learning Conceptual Framework

In 1998, Black and Wiliam published the article, Inside the black box: Raising standards through classroom assessment, which is recognized as a quintessential piece on the effectiveness of formative assessment. Black and Wiliam (1998) used material from 250 studies on assessment conducted around the globe to answer three important questions:

1. Is there evidence that improving formative assessment raises standards?

2. Is there evidence that there is room for improvement?

3. Is there evidence about how to improve formative assessment? (p. 140) The answer arrived at was yes for each of these questions, more importantly, Black and Wiliam (1998) clearly noted the belief formative assessment should not be viewed as a quick fix, but rather as part of a larger body of good classroom practices. Black and Wiliam (1998) stated, "However, we also acknowledge widespread evidence that fundamental change in 
education can be achieved only slowly-through programs of professional development that build on existing good practice" (p. 140). Black and Wiliam emphasize the need for formative assessment to be viewed as a part of sound classroom practice and supported professional development for teachers is essential for improvement in student learning.

Black and Wiliam (1998) analyzed the learning gains of students in classrooms where formative assessment was in practice and compared them to students in classrooms where formative assessment was not in practice. Learning gains were measured by comparing the average improvement on test scores of both student groups. Black and Wiliam (1998) found, "Typical effect sizes of the formative assessment experiments were between 0.4 and 0.7 . These effect sizes are larger than most of those found for educational interventions" (p. 141). For perspective on what an effect size of 0.7 would have meant for U.S. education in 1998, this type of improvement would have raised U.S. test scores from ranking of $41^{\text {st }}$ to the top five on an international comparative study of mathematics (Black \& Wiliam, 1998). Clearly, formative assessment can raise the achievement standards of students.

Research evidence indicates formative assessment is not currently in practice in the everyday classroom (Black \& Wiliam 1998; Black et al., 2004; Brookhart, 2004; Stiggins et al., 2006). External pressures from the political arena in the form of national and state testing drain resources from professional development programs to fund these massive assessment tools. Black et al. (2004) noted this problem:

In the U. S. similar pressures have been felt from political movements characterized by a distrust of teachers and a belief that external testing will, on its own, improve learning. Such fractured relationships between policy makers and the teaching profession are not inevitable-indeed, many countries with enviable educational 
achievements seem to manage well with policies that show greater respect and support for teachers. (p. 142)

Clearly, political commitment to competition through testing is a priority, but the commitment to formative assessment is marginal. Due to these external pressures and misappropriation of assessment resources there is much room for improvement in the understanding and use of formative assessment.

Most teachers have heard of, or know something about, formative assessment, but do not implement the practice in their classrooms. Chappius (2005) noted, "During the last decade, many schools have begun to emphasize formative assessment" (p. 39). However, as teachers work to develop common assessments, and engage in data-driven decisions they continue to remain central in the decision making role about student learning. Chappius (2005) stated, "This approach reflects the underlying assumption that teachers control learning” (p. 39).

Three other common teacher misconceptions prevent formative assessment from becoming common practice (Moss \& Brookhart, 2009). First, teachers often believe formative assessments are a special test or series of tests that teachers use to find out what their students know. This misconception stems from the interchangeable use of assessment and tests. Secondly, formative assessment is an add-on program that teachers adopt into their current practice. This misconception stems from years of traditional inservice workshops which have teachers employ a technique or program into their current practice. Lastly, teachers often believe any practice that gathers information to improve a program or teaching is a part of formative assessment. This misconception stems from a belief that the role of assessment is to modify instruction or lesson design, not to improve student learning. 
For teachers to see true improvement in their students learning they need to assist students' in answering three key questions: Where am I going?; Where am I now?; and How can I close the gap? (Chappius, 2005; Moss \& Brookhart, 2009; Stiggins et al., 2006).

Stiggins et al. (2006) stated,

"Assessment for learning is an interplay between teachers and students. Students are active, not just as test taker, but in thinking about their learning. We want all students to engage in and take responsibility for their learning, and we can take specific steps to help students answer assessment for learning's three questions..." (p. 41). The key to the aforementioned statement is the phrase interplay between teachers and students. This idea is what draws students out of the role of passive receivers of knowledge to active participants in the dialogue about not only content, but their own learning. Stiggins et al. (2006) and Chappius (2005) identified what they call The Seven Strategies of Assessment for Learning. The three questions and the corresponding seven strategies, which undergird them, are what comprise the framework for assessment for learning in the classroom (Stiggins et al., 2006).

Where am I going? The first of the three questions is supported by two strategies (Stiggins et al., 2006). The first, students need to be given clear and understandable vision of the learning target. Simply writing the objective on the board is not good enough; students need to be informed of the learning target in terms which can be translated to action. Moss and Brookhart (2009) noted, "The single most important method for routinely sharing learning targets is using assignments that really match the learning goal” (p. 25). By matching assignments with learning goals, students come to believe if they can do the assignment, they can do the learning objective. Secondly, students should be given clear 
examples of both strong and weak work. Stiggins et al. (2006) wrote, "Begin with work that demonstrates strengths and weaknesses related to problems students commonly experience, especially the problems that most concern you" (p. 43). This strategy helps students get a clear vision of what the product or performance looks like when done well.

Where am I now? Students need quality information about where they are at in relation to the learning target. This is best served by the strategy of offering students' regular, descriptive feedback about their progress toward the learning target the assignment is designed for (Chappius, 2005; Moss \& Brookhart, 2009; Stiggins et al., 2006). Research has established student learning can be advanced by feedback through comments; however, the giving of numerical scores has a negative effect because students ignore feedback when grades are given (Black et al., 2004). More importantly, feedback supports student metacognition which increases their awareness about their thinking and the use of self awareness to regulate thinking (Moss \& Brookhart, 2009). Along with self-awareness, students need to understand how to self assess and set goals which help them reach learning targets. Goal setting and self assessment in relation to the learning target allow students, especially low achieving, to make positive gains in their learning (Black et al., 2004; Chappius, 2005; Moss \& Brookhart, 2009; Stiggins et al., 2006).

How can I close the gap? When students are taught how to analyze their own work in relation to learning targets they can successfully design strategies which help them achieve the target. Teachers can assist students in closing the gap by focusing on one part of quality work at a time (Stiggins et al., 2006). Chunking course content into essential skills students need to know, allowing time for adequate practice, and providing feedback helps students gain self-efficacy (Moss \& Brookhart, 2009). Feedback also plays a critical role in teaching 
students focused revision of their work. Focused revision assists students in reaching the learning target by alleviating the sense of hopelessness some students feel when success is not immediate. Allowing students to share their learning with other students creates a collaborative environment where students develop insight into themselves as learners. More importantly, the student, not the teacher, is the one doing the work and thinking about how to reach the learning target.

Clearly, assessment for learning takes careful planning, reflective practice, and assignments that link learning to identifiable learning goals. Unfortunately, teacher use of assessments as a method to audit students, not promote their learning, is hampering the effectiveness of classroom assessments (Moss \& Brookhart, 2009). Classroom assessments can take many forms including, but not limited to: projects, performance events, oral presentations, and homework. A particularly problematic classroom assessment is homework. Often homework is given to students with the intent of extending learning, but if careful planning is not done it can have the opposite effect (Vatterott, 2009). If students are to benefit from homework as extension of learning time then teachers need to understand how it can be a powerful tool in the formative assessment process.

\section{The Current Practice of Homework as Assessment}

Homework is the most prevalent and problematic form of teacher driven classroom assessment utilized in the school setting. Vatterott (2009) stated, "Homework began generations ago when schooling consisted primarily of reading, writing, and arithmetic, and rote learning" (p. 1). Homework is a long standing educational tradition which, until recently, has seldom been questioned (Vatterott, 2009). Homework is generally seen as a positive practice and accepted without question as part of the student routine. The history and 
attitudes toward homework are deeply entrenched despite multiple shifts in societal viewpoints toward homework over the last 110 years of education history (Vatterott, 2009). The History and Culture of Homework

In the late $19^{\text {th }}$ century and into the early $20^{\text {th }}$ century many students left school before the eighth grade. During this time, a majority of first to eighth grade student assessments required simple rote memorization. Reading, writing, and arithmetic skills were developed through drills which were repeated again and again at school, therefore, homework was rarely given. However, if a student was fortunate enough to continue into high school, the demands of homework extended beyond the school day and stood in direct conflict with the societal need for children as workers. Additionally, the rise of pediatric medicine put doctors in the forefront of the campaign to limit time spent on homework outside of school (Vatterott, 2009). This negative attitude toward homework persisted well into the 1940s with many school districts across the country banning homework all together.

The national attitude toward homework changed with one historic and symbolic event in 1957, the launch of the Sputnik satellite by the Soviet Union. Gill and Schlossman (2004) noted this pivotal moment in the following words:

The homework problem was reconceived as part of a national crisis: the U.S. was losing the Cold War because Russian children were smarter; that is, they were working harder and achieving more in school...the new discourse pronounced too little homework an indicator of the dismal state of American schooling. A commitment to heavy homework loads was alleged to reveal seriousness of purpose in education; homework became an instrument of national defense policy (p. 176). 
Public opinion shifted away from a negative view of homework to one where homework was considered essential for increased student learning (Vatterott, 2009). With the reintroduction of homework as a staple of instruction came the reemergence of opposition to excessive homework assignments. Two prominent education organizations of the time published their recommendations on the length of time students should be asked to dedicate to homework. In 1966, the National Education Association (Wildman, 1968) issued a statement:

It is generally recommended (a) that children in the early elementary school have no homework specifically assigned by the teacher; (b) that limited amounts of homework-not more than an hour a day-be introduced during the upper elementary school and junior high years; (c) that homework be limited to four nights a week; and (d) that in secondary school no more than one and half hours a night be expected. (p. 204)

Similarly, the American Educational Research Association (Wildman, 1968) stated: Whenever homework crowds out social experience, outdoor recreation, and creative activities, and whenever it usurps time that should be devoted to sleep, it is not meeting the basic needs of children and adolescents. (p. 204)

These recommendations mirrored the national subculture of challenging the status quo which was sweeping the nation in the late 1960s and early 1970s. Parents of the time were demanding children be free to play and relax in the evenings (Vatterott, 2009). However, it would not be long before this attitude toward homework would be changed once again with one document destined to change the assessment debate.

In 1983, the publication of $A$ Nation at Risk created a sense of urgency throughout the educational community with its claim of a rising tide of mediocrity within American schools 
(National Commission on Excellence in Education, 1983). Vatterott (2009) noted, "A Nation at Risk explicitly calls for 'far more homework' for high school students" (p. 7). The U.S. Department of Education published What Works, in 1986, which called for homework as an effective learning strategy (Vatterott, 2009). With these two publications the culture of classroom assessment known today was born and continues with almost unabated fervor. Kohn (2006) noted this emphasis on homework as a perceived tool for improvement, "Whenever you come across a particularly savage attack on the state of public education, it's a safe bet that a call for more homework (and other get-tough messages) will be sounded as well” (p. 120).

\section{Research on Current Homework Practice}

Only within the last 15 years has the discussion on the true value of homework and how to improve the use of homework by teachers begun in earnest. Learning theory supports increasing the amount of time students spend on learning, however, more time does not always correlate to better achievement. Homework does supply additional time, but does not account for a lack of prior knowledge or slower working speeds. Just because higher achieving students do more homework or lower achieving students are given homework does not mean learning has taken place (Guskey \& Bailey, 2001; O'Connor, 2002).

Cooper (2007) published an article which was a meta-analysis of several studies on homework as well as his own research on the topic. Depending upon the statistical analysis used and the variables controlled for, homework can be found to have a positive correlation with achievement, or a minimal correlation. When achievement levels of the student (i.e., class ranking or grades) are controlled for there has been very little evidence which supports the notion homework increases student achievement (Vatterott, 2009). Cooper's (2007) 
article is often cited in scholarly research; unfortunately, his recommendations for secondary students are not based on causation, but rather correlation. Kohn (2006) created a good analogy when he declared:

Statistical principles don't get much more basic than “correlation doesn't prove causation." The number of umbrellas brought to a workplace on a given morning will be highly correlated with the probability of precipitation in the afternoon, but the presence of the umbrellas didn't make it rain...Nevertheless, most research purporting to show a positive effect of homework seems to be based on the assumption that when students who get (or do) more homework also score better on standardized tests, it follows that the higher scores were due to their having had more homework. (p. 28)

The belief in the innate goodness of homework is why researchers continue to recommend homework as a key component of the classroom environment despite their findings to the contrary (Kohn, 2006). Despite the limitations of research on homework there are two bodies of knowledge which can alter the use of homework (Vatterott, 2009). One, there is a large amount of research on how children learn, and this research can lend insight on how to design proper homework which supports learning. Two, reflective practice on their classroom experiences can assist teachers in intuitively understanding what works and does not work. However, this knowledge alone cannot alter practice. Teachers need to understand how homework can increase student learning when it is used as one effective form of assessment for learning. 


\section{Homework as Assessment for Learning}

A common complaint about homework from teachers is students do not complete some or all of the homework assignments given to them. Many teachers believe this is a motivation problem on the part of students when in fact reflection on current practice could help. Vatterott (2009) stated, "Many strategies exist to improve the rate of homework completion, but before discussing those strategies, we must rethink how common practices may contribute to the problem" (p. 87). As has been examined in earlier sections of this paper, traditional beliefs and attitudes permeate classroom assessment practice. Leadership and dialogue on these beliefs and attitudes can assist teachers in their progress toward understanding how to effectively use homework. Additionally, examination of research on assessment for learning and homework can guide teachers toward a better understanding of not only assessment, but the student learning process.

Many years of research has shown students differ in their readiness and developmental level and that all students do not learn in the same way, despite this information, teachers continue to apply a one-size-fits-all approach to homework (Eisner, 2003-2004). Learning theory has also indicated students differ in their working speed which

results in some students spending more time on homework than others. The remedy teachers use for this problem is often to give a child more time not less work (Goldberg, 2007). Combine these factors (differing readiness, variable working speed, and more time not less work) with grading practices that treat learning as a discipline situation, and educators create a situation where students fail. Zeroes in the grade book become the teacher's ultimate weapon in an attempt to get students to complete work and to motivate them to learn (Guskey, 2004b). 
All educators would agree the goal for students is for them to have self-discipline, to perfect their intellectual skills, and to feel confident as learners (Vatterott, 2009). Students who do not complete homework can begin to experience gaps in learning which become greater over time and diminish their motivation to learn. An achievement gap already exists between social classes and racial groups, poorly designed homework assignments only compound this problem into consistent failure (Vatterott, 2009). It is imperative teachers design quality homework tasks which promote the learning process.

Quality homework should be infused with the guiding questions and strategies set forth by assessment for learning research. Vatterott (2009) stated, "As teachers consider the academic purpose of a particular homework task, they should focus less on the quantity of work they are expecting and more on the quality, keeping the focus on mastery of essential concepts and skills" (p. 100). This concept links directly to Strategy Five described by Stiggins et al. (2006), "Design lessons to focus on one aspect of quality at a time" (p. 44). Teachers need to make students cognizant of the learning target the homework is designed for as well.

A goal of homework is to ensure students feel positive about learning and develop an identity as successful learners (Vatterott, 2009). Homework assignments should be designed to serve two important functions, the support of classroom learning and a sense of competence in the mind of the student (Sagor, 2002, 2008). Demotivation of students through repetitive assignments causes them to pull away from the learning process and inhibits selfefficacy (Darling-Hammond \& Ifill-Lynch, 2006). Homework needs to be supported through consistent feedback, student revision of assignments, and student interaction about their work. 
Students should view homework as vital to their learning; however, as long as students feel homework is something being done to them, it is the teachers work, not theirs. For students to feel ownership in their learning they need the opportunity to set goals, reflect, on their progress, and to adjust their learning goals (Moss \& Brookhart, 2009). Self-reflection on learning provides students with a sense of power over their learning, how they learn it, and to show how they learned it (Guskey \& Anderman, 2008). However, self-reflection should not be limited to students, if students will not complete a homework task, teachers need to ask if the task was appropriate (Kohn, 1999, 2006).

Homework assignments that do not differentiate for individual differences in student abilities, learning styles, structure or scaffolding, and difficulty undermine student motivation (Tomlinson, 2003). If teachers are employing the seven strategies found within assessment for learning then it is obvious homework should follow these guidelines. By creating homework tasks which are to be given to all students without concern for their differences teachers remain in contrast to assessment for learning strategies. Each of the seven strategies has a direct link to the necessity for differentiated homework. From strategy one, clear learning targets, to strategy seven, self-reflection, quality homework assignments account for individual differences and needs of each student.

A change in homework practice will take leadership skills which match the task of altering the culture of a century of assessment beliefs. The traditional methods of assessment, grading, and homework are entrenched in the beliefs, attitudes, and assumptions of teachers, parents, and school administrators. Perhaps the most influential group to emerge into the discourse on assessment has been politicians. If school leaders are to change the practices 
they see each day in the classrooms of their buildings leadership grounded in transformation and learning will be needed.

\section{Leadership and Change in Organizations}

Close to a hundred years of writing and research has failed to identify a single definition of leadership. Leithwood and Duke (1999) posed the following statement and question: "One wonders how so many smart people could have overlooked such an obvious issue. Or did they?" (p. 46). Lofti Zadeh, the father of fuzzy logic, lends insight as to why leadership is so hard to define with his Law of Incompatability: As complexity rises, precise statements lose meaning and meaningful statements lose precision (McNeil \& Frieberger, 1993). The Law of Incompatability helps to point why complex concepts are best described in vague terms and simple concepts are defined with a succinct statement (Leithwood \& Duke, 1999). Undoubtedly, leadership is a complex set of behaviors and actions that has always presented researchers with the difficult task of identifying what comprises effective

leadership. The most effective leaders often demonstrate similar behaviors while at the same time behaviors which are very different. Contemporary leadership models reflect this same dichotomous relationship.

Over the last century, leadership has intrigued scholars and created an evolution of leadership theory into many different models. Countless researchers have studied and espoused leadership theories which have been identified as the key to organizational success. Interestingly, given all the research on leadership it is impossible and perhaps unwise to define what comprises leadership in one sweeping definition. Yukl (2006) stated "when leadership is defined in a restrictive way by researchers, they are likely to take a narrower perspective on the processes to be studied, and it is less likely they will discover things 
unrelated to or inconsistent with their initial assumptions about effective leadership" (p. 21). A definition of leadership may be difficult to narrow, but one aspect of leadership, influence, is evident in all definitions (Burns, 1978; Yukl, 2006).

Leaders can use influence differently when engaging in one of several different types of leadership models. Leithwood and Duke (1999) identified six models of leadership after analyzing a sample of contemporary articles: instructional, transformational, moral, participative, managerial/strategic, and contingency. None of these models provide the best approach to leadership for current and future school leaders to productively respond to the challenges they may face (Leithwood et al., 2000). Transformational leadership, however, does serve as a point of departure for developing a comprehensive approach to present and future leadership practice (Leithwood et al., 2000).

Transformational leadership can shape, alter, and elevate the motives, values, and goals of the followers through the vital teaching role of leadership (Burns, 1978). Burns described two sets of values which contribute to the attainment of higher goals; modal and end values. These are two important forms of values public school administrators need to cognizant of and assist organizational members in learning their worth in creating a positive learning environment. Modal values are defined by terms such as honesty, responsibility, fairness, and the honoring of commitments. End values are defined by terms such as justice, liberty, and equality.

In describing transformational leadership, Burns (1978) stated,

The premise of this leadership is that, whatever the separate interests persons might hold, they are presently or potentially united in the pursuit of 'higher goals', the 
realization of which is tested by the achievement of significant change that represents the collective or pooled interests of leaders and followers" (pp. 425-426).

The pursuit of higher goals, such as equity and justice, creates a close parallel between the concept of moral leadership and transformational leadership. Burns (1978) stated, "A primary leadership role or function is to increase awareness about ethical issues and help people resolve conflicting values" (p. 20).

Both moral and transformational leadership pursue the elevation of follower behaviors toward higher goals, however, the emphasis in moral leadership is on the morals and ethics of those in formal leadership roles (Leithwood \& Duke, 1999). Therefore, the key distinction between these two theories is moral leadership focuses on the values and ethics of the leader, so authority and influence are derived from what is right or good, where transformational leadership focuses on the commitments and capacities of organizational members. This distinction is a fine line since transformational leadership is morally bound by the values identified by Burns (1978), but not limited by just the values of the leader.

The capacity of any organizational member to influence the organization becomes the counterbalance to what can be a potential pitfall of moral leadership, poor moral development. Leaders at the lowest levels of moral development are motivated by self interest and the satisfaction of personal needs which do not allow them to move themselves or others toward end values (Yukl, 2006). Leaders at the highest levels of moral development are motivated to fulfill internalized values and moral principles which allow them to move themselves and others toward end values (Yukl, 2006). Organizational leaders who do not develop morally are in a position to do significant damage to themselves and the organization instead of transforming the organization into an institution for social justice. 
Transformational leadership emphasizes how a collective commitment to organizational goals creates a capacity for change in the organization not limited to those in formal authority positions, but within all organizational members (Leithwood et al., 2000). Leithwood et al. (2000) stated, “...power is attributed by organizational members to whomever is able to inspire their commitments to collective aspirations and the desire for personal and collective mastery of the capacities needed to accomplish such aspirations" (p. 9). The ability of any organizational member to have the power of influence within an organization is an important concept found within transformational leadership.

Leithwood and Duke (1999) developed the concept of transformational leadership beyond those attributes mentioned previously into seven dimensions: building school vision, establishing school goals, providing intellectual stimulation, offering individualized support, modeling best practices and important organizational values, demonstrating high performance expectations, creating a productive school culture, and developing structures to foster participation in school decisions. Additionally, there are several behavior components which allow leaders to create this effort. Bass (1985) identified three types of behavior which transformational leaders use to inspire followers. Idealized influence is behavior which arouses strong emotions and identification with the leader. Intellectual stimulation is behavior which increases follower awareness of problems and encourages followers to view problems from various perspectives. Individualized consideration involves providing support, coaching, and encouragement to organizational members. Bass and Avolio (1990) added a fourth behavior, inspirational motivation, which includes communicating an appealing vision, using symbols to focus effort, and modeling desired behaviors. Educational leaders who wish to initiate change need to employ transformational leadership principles. Two 
important sets of criteria for the use of transformational leadership are the four behaviors identified by Bass and Avolio (1990) coupled with Leithwood and Duke's (1999) seven dimensions.

Yukl (2006) identified six guidelines for leaders seeking to use transformational leadership: articulate the vision, explain how the vision can be attained, act optimistic and confident, express confidence in followers, use dramatic, symbolic actions to emphasize key values, and lead by example. Transformational leadership proposes leaders use stories, symbols, slogans, and imagery to influence followers to aspire to a collective commitment to higher goals (Yukl, 2006). The six guidelines listed above have a distinct relationship with Bolman and Deal's (2003) cultural frame and Yukl's charismatic leadership traits.

In contrast to transformational leadership, charismatic leadership employs a strong use of power to attain follower loyalty (Yukl, 2006). The charismatic leader's need for power can often create a polarization within the organization; therefore charismatic leadership is not always effective in all situations. Transformational leadership has the capacity to be utilized in many situations, not just crisis situations as is often the case in charismatic leadership (Yukl, 2006). Charismatic leadership, with its emphasis on power not teaching, does not have the ability to produce long term, systemic change through engagement of followers in the critical examination of current practice, unlike transformational leadership. Interestingly, with all the positive aspects transformational leadership can bring to a leader's ability to change the organization there is a crucial organizational analysis lens which cannot be overlooked, politics.

Burns (1978) stated often leaders are seen as leading followers but do not understand leaders may be modifying their leadership in recognition of followers' preferences or in 
anticipation of followers' responses. Burns alludes to the power and influence found within the political frame which can often be overlooked by leaders whose focus is solely on culture and structure. Bolman and Deal (1991) pointed out educational leaders typically do not employ political and symbolic/cultural frames when interpreting problems instead focusing on structural and human resource as a base for what needs to be done.

Davis (2003) noted leadership which is primarily symbolic seldom produces significant organizational change. Leaders using transformational leadership need to be aware of the political elements within the organization. Political awareness allows leaders to understand the influence they can exert and the influence being exerted upon them by those they are leading. Leaders who appreciate the motives of followers create situational awareness which can provide an ability to be productive in a variety of situations.

Through the vital role of teaching and the use of conflict, current values held by organizational members have been challenged with the intended outcome being the attainment of higher goals (Burns, 1978). This is a difficult task for school leaders to undertake given organizational members create their assumptions based on a narrow personal experience and often fail to comprehend the important function education can play in promoting equity. As a result, school leaders need to understand the crucial role conflict plays in the organizational change process. Conflict creates the opportunity for followers to learn about and appreciate issues from various perspectives. As Burns (1978) noted:

Only with time, determination, conviction, and skill and with the indispensable element of conflict can followers be drawn out of these narrower collectives and into 'higher' purpose and principle validated by the enduring criteria of justice and humanity and forged in an open and continuing conflict of values. (p. 429) 
As organizational members and leaders move toward the understanding of new perspectives they can begin to change the culture, politics, and systems of the educational environment in which they find themselves.

Yukl (2006) stated transformational leadership induces followers to transcend selfinterest in pursuit of organizational success. Constantly changing educational expectations have fostered a need for leaders who can develop follower skills and confidence in preparation for them to take more responsibility in an empowered organization (Yukl, 2006). When organizational learning and commitment to organizational success become the focal point for all members' significant change becomes possible.

An example of learning and commitment higher goals could be the examination of current educational practice. Are some practices, policies, and procedures inhibiting equality for all students in the educational setting? Are educators ready to critically reflect on those practices and change them in order to serve all students? Brown (2004) and Shields (2004) both supported the use of transformational leadership as a model to promote social justice within the educational setting. Educational administration programs need to begin to utilize pedagogy which engages potential leaders in learning how the issues of power and privilege restrict opportunities for certain groups and how leaders can be advocates for social change (Brown, 2004). Educational leaders should have the ability to engage teachers in dialogue which examines and challenges the status quo currently restricting a more equitable educational system for all students (Shields, 2004).

Over the last decade equity has become an emerging theme in public education. The passage of the American Competitiveness Initiative and No Child Left Behind has made an equitable education for all students a federal mandate. These two items have forced educators 
to rethink current classroom practice; however, the reliance on state or national assessments as data for improvement is not having the desired impact on student achievement. These assessments of learning provide brief and, in most cases, delayed measures of student achievement. What teachers need to improve practice is day to day information on student learning, not information which is four to six months old as is the case with most standardized tests. If teachers are to improve their classroom instruction a transformation in classroom assessment is one part of the solution.

As has been examined earlier in this chapter, transformational leadership has, as part of its theoretical base, the influence leaders have over the members of the organization. Through the vital role of teaching, leaders are able to alter, shape, and elevate the values and goals of followers (Burns, 1978). Importantly, this change in values and goals cannot be attained without conflict. Conflict can arise both internally, based on organizational members' assumptions and beliefs, and externally from the demands placed on the organization by society. School leaders need to be aware of the assumptions of teachers and provide learning opportunities which challenge these assumptions. Assessment, in particular homework, is a classroom practice primarily derived from the experiences of teachers as students or from mentor teachers who had an impact on their early experiences as a teacher.

Research into current teacher homework practices and teacher perception of the role of homework can provide school leaders the necessary information to transform how homework is utilized in the classroom. This knowledge in concert with a sound professional development program based on the transformational leadership principles of intellectual stimulation, individualized support, modeling of best practice, and structures which foster participation in the school decision making process would allow school leaders to influence 
teachers toward a new vision of homework (Leithwood \& Duke, 1999). Additionally, school leaders will need to guide teachers toward a new set of symbols, stories, and imagery representative of a new homework model (Yukl, 2006). For school leaders to affect this change in homework practice, application of the concepts of organizational learning will need to be utilized.

\section{Organizational Learning and Assessment}

The explosion of information over the last 100 years has shifted the world into a global information society. Organizations are now in a never ending race to create and distribute the growing commodities of information and new knowledge. The means by which an organization views knowledge creation can denote the difference between innovation and success or stagnation and failure. According to Nonaka (1994), the most successful modern organizations are those who have moved away from the old perspective that information is processed, to a view where knowledge is created.

Previous theories of organizational knowledge were founded on the assumption that the organization existed to process information quickly in order to react to uncertain and rapidly changing environments. These older theories of organizational knowledge rely heavily on hierarchical information processing and view information dispensation as a problem solving activity. While problem solving may be a function of an organization; organizational learning, the creation of new knowledge through collaborative efforts, and dialogue on critical issues facing organizations can have a transformative effect on an organization.

Nonaka (1994) argued that organizations not only need to process information efficiently but must also create information and knowledge. The organization's interaction 
with its environment, along with the means by which it creates and distributes information and knowledge, are important in relation to building an active and dynamic understanding of the organization. Therefore organizations should be cognizant of how they create information, rather than solely on how it is processed (Nonaka, 1994). New and innovative concepts are often formed in the mind of an individual, but it is the relationship between individuals which plays a critical role in developing new knowledge and learning. Bruffee (1999) highlighted the importance of conversation as a necessary component of learning. The relationship between conversation and thought is the interaction which constructs and maintains the community's knowledge (Bruffee, 1999). It is within the social interplay of organizational members where the dynamic of knowledge creation can be applied to organizational learning. Nonaka (1994) called this relationship "communities of interaction" (p. 15). These communities can appear in a variety of forms within the organization such as departments, groups, and teams.

Kasl, Marsick, and Dechant (1997) advanced the idea of group, community or team learning. They believe team learning is a process by which groups create knowledge for members, for the organization, and for self. For teaming to be effective, however, Nonaka (1994) argued that social interaction and conversation are necessary ingredients for the development of new knowledge. Within learning organizations, social interaction contributes to the amplification and development of new knowledge. Eraut (2004) noted the majority of learning in the work place was informal and involved not only learning from others, but also from personal experience. Nonaka (1991) stated, "Knowledge creation depends on tapping the tacit and highly subjective insights, intuition and hunches of individual employees and making those insights available for testing and use by the organization as a whole" (p. 97). 
Two important knowledge creation and learning terms which have emerged from research are tacit knowledge and explicit knowledge. Polanyi (1966), an early pioneer in the field of knowledge creation, first described tacit knowledge and explicit knowledge and how they differ from each other. Tacit knowledge is grounded in personal experience, ideals, values, and emotions which can make it difficult to share with others. Explicit knowledge, which is described as codified knowledge in the form of words and numbers, can easily be transmitted between individuals (Polanyi, 1966). Explicit to explicit knowledge creation occurs when an individual synthesizes information from a variety of sources and creates new knowledge, though this knowledge creation is important, it does not add to the knowledge base of the organization (Nonaka, 1994).

Tacit to tacit knowledge creation occurs when one individual shares tacit knowledge directly with another (Nonaka, 1991). A key component of new knowledge creation is the synthesis of explicit knowledge into tactic knowledge which results in new information being shared with the organization as a whole. Once the new knowledge is shared and employees start to internalize it, they begin to use it to broaden, extend, and reframe their own tacit knowledge (Nonaka, 1991). Articulation and internalizing explicit knowledge to increase one's own tacit knowledge base are critical steps in what Nonaka termed the spiral of knowledge. More importantly, knowledge creation cannot occur without social interaction and conversation.

Mezirow (2000) stated, "Communicative learning often involves a critical assessment of assumptions supporting the justification of norms" (p. 9). For adult learning to take place, contextual understanding, critical reflection on assumptions, and validating meaning by assessing reasons need to be a part of the dialogue within an organization. The power of 
personal experience and the assumptions, values, ideals, and thoughts created in one's life forms a potential barrier to organizational learning. Past experiences define individual understanding and help us to avoid the threat of chaos (Mezirow, 2000). "If we are unable to understand, we often turn to tradition, thoughtlessly seize explanations by authority figures, or resort to various psychological mechanisms, such as projection and rationalization, to create imaginary meanings" (Mezirow, 2000, p. 3). The team dialogue format allows the opportunity for organizational members to engage in a non-threatening environment where assumptions and past experiences can be examined for their validity in current practice.

This is an important first step in developing a collaborative culture where discourse on issues could occur. As Mezirow (2000) noted, "Our culture conspires against collaborative thinking and the development of social competence by conditioning us to think adversarially in terms of winning or losing, of proving ourselves smart, worthy, or wise" (p. 11). Therefore, it is important to build collaborative structures which emphasize the importance of embracing difference, tolerating inevitable paradoxes, finding the common in the midst of disagreement, and reframing one's assumptions (Mezirow, 2000). When these concepts are put into action, learning can take place within an organization and new knowledge can be created which will have transformative effect on the organization and the members found within.

Contained in the preceding section are concepts which have significant implications for individuals in leadership roles who aspire to transform education and the learning experiences of both teachers and students. The work of Nonaka (1991, 1994), Bruffee (1999), Mezirow (2000), and others emphasize the importance of social interaction and communication as a central component of organizational learning. Morgan (2006) noted 
"part of the challenge hinges on adopting an appropriate management philosophy that views and encourages the capacity of learning to learn as a key priority" (p. 97). School leaders need to create systems where discourse among the members of the organization coupled with an influx of knowledge becomes the method for understanding the importance of learning.

How can educational leaders break down the barriers to successful collaboration and ultimately foster a learning organization? Bruffee (1999) coined the term "reacculturation" (p. 136) as one method to begin the process of changing organizational culture into a collaborative environment. Conversation at the boundaries of two individual communities of knowledge and the understanding that is a result of learning about each other is what reacculturation is about. It is through this understanding of the uniqueness of each individual's experience by which the change process toward the creation of a learning community can take root. Collaborative, conversational environments where educators rely on one another are a paradigm shift for most secondary schools.

A cultural shift toward a learning environment where interdependence between individuals is a norm can be difficult given the isolationist culture of most secondary school environments. Interdependence can alleviate the resistance to cultural change if leaders create systems of dialogue among diverse members of the organization. Bruffee (1999) affirmed this notion stating:

This transitional process of translation, this willingness to learn the elements of new languages and gain new expertise, is the most important skill in the craft of interdependence. It is a willingness to become members of communities we have not belonged to before, by engaging in constructive conversation with others whose background and needs are similar to our own but also different. (p. 12) 
Those who choose to accept the challenges of leadership need to be cognizant of the pitfalls and power of cultural change as a method to enhance learning. As Morgan (2006) noted in his metaphorical analysis of organizations as psychic prisons, "Culture gives us our world. And it traps us in that world!" (p. 211). Persistent effort towards the creation of collaborative teams and constructive dialogue as a part of organizational culture is essential to learning. Cultural change alone, however, will not produce a social, interdependent group of learners there should be structural change to produce time for collaborative opportunities, as well.

School leaders must create what Mezirow (2000) termed spaces where conversation can take place on issues and ideas essential to improving organizational effectiveness. A fundamental problem, however, is organizational members often view change with trepidation and stability as preferred. Bolman and Deal (2003) pointed out a flaw in this stance when they stated, "Organizations are reluctant to make major changes because a stable structure reduces confusion and uncertainty, maintains internal consistency, and protects the exiting equilibrium. The price of stability is a structure that grows increasingly misaligned with the environment" (p. 85).

For the last century classroom assessment practice has been stable due to the tradition rich environment in which it exists. The introduction of national, state, district, and local standardized assessment have done little to impact the classroom and teacher assessment practice. The result is a crisis in assessment practice (Stiggins, 2002). If there is a crisis, as Stiggins proclaims, then why are teachers reluctant to change the way in which they use homework as an assessment tool? Cultural norms have prevented the realization of the assessment crisis and hindered a change in assessment practice. More importantly, school 
leaders have failed to provide the leadership and learning opportunities which allow for new norms, traditions, and values to take root.

The increased demand to educate all students to high levels has necessitated the need for teachers monitor student learning and adjust classroom practice to improve student learning. Homework, when used formatively, is one form of classroom assessment which can give teachers a powerful tool to increase student achievement. Moss and Brookhart (2009) noted,

Formative assessment can have a transformational effect on teachers and teaching. In a very real way it flips a switch, shining a bright light on individual teaching decisions so that teachers can see clearly the difference between the intent and the effect of their actions. (p. 10)

School leaders need to utilize the principles of reacculturation, knowledge creation, and conversation as a method to improve homework assessment practices. This can be done when school leaders understand the importance, gain the expertise, and implement the principles of a learning organization capable of fostering transformative learning for individuals and, simultaneously, breaking past patterns of action by requiring entirely new behaviors on the part of all organizational members (Mezirow, 2000). The limited research into teacher understanding and perceptions of homework as formative assessment inhibits the ability of school leaders to engage teachers in critical discourse capable of producing change. Research into this area will allow leaders to understand how to influence not only individual teacher homework practices, but the entire organizations approach to homework as well. 


\section{Summary}

The literature review presented above contained information on assessment for learning concepts, homework as a form of assessment, transformational leadership theory, and adult learning theory. The breadth of information on each of these topics made it impossible to contain all information found on each. In order to give focus to the literature review, the paper concentrated on how transformational leadership theory and adult learning theory can influence a change in homework practice.

Chappius (2005), Moss and Brookhart (2009), and Stiggins (2008) research into assessment for learning gave a knowledge base for how to utilize the concepts on homework presented by Vatterott more productively in the classroom. This information provided the foundation from which to explore teacher perceptions, understanding, and use of homework in classroom assessment. Transformational leadership and adult learning theory lend insight into how school leaders can positively impact homework as assessment with the information gained from teacher responses to the research questions.

The literature review in this chapter provided support and validation for the use of a qualitative study to gain valuable information on teacher perceptions, understanding, and use of the homework as a part of classroom assessment in the Midwestern United States. By investigating how teachers perceive, understand, and use homework as classroom assessment school leaders will gain insight on how to use transformational leadership and adult learning theory to change current practice. Chapter Three details the methodology associated with

qualitative research and provides the research design to accomplish the purpose of the study. 
The emergent findings and discussion of the findings will be found in Chapters Four and Five. The subsequent chapter will contain appendices which contain informed consent, online teacher survey, and teacher focus group interview protocol. 


\section{CHAPTER THREE}

\section{RESEARCH DESIGN AND METHODOLOGY}

\section{Introduction}

Formative assessment can have a truly transformative effect on the classroom environment. Moss and Brookhart (2009) stated, "When teachers join forces with their students in the formative assessment process, their partnership generates powerful learning outcomes. Teachers become more effective, students become actively engaged, and they both become intentional learners" (p. 5). Classroom assessment takes on many forms quizzes, tests, and homework are all examples. The latter, homework, is an iconic fixture within the classroom environment and is an assessment practice in desperate need of reform.

Stiggins (2008) noted a crisis in American assessment practice and called on educators to reevaluate current practice. The plethora of research into proper assessment practices has been thoroughly research, but research into how homework, specifically, can be used as a formative assessment tool is limited. In particular, research into how teachers perceive, understand, and use homework as a formative assessment tool was not found. Furthermore, teacher expectations of the role school leaders should play with regards to leading improvement in this critical aspect of education was not found. The purpose of this study was to investigate and understand teacher perceptions, understanding, and use of homework as a formative assessment tool and how teacher expectations of school leaders in leading improvement in assessment. In this chapter, the methodology to be used for the study will be discussed and the research questions to be explored will be listed.

Qualitative research takes place in the natural setting of the participants to be studied (Creswell, 2003). The use of multiple methods which are interactive and humanistic allows 
the researcher to build relationships and gain credibility with those involved in the study (Rossman \& Rallis, 1998). This research explored teacher perceptions, understanding, and use of homework as formative assessment in Midwestern secondary schools. The researcher has no knowledge of prior research on this topic. Results from this research could be of benefit to school leaders by enhancing the understanding of how teachers currently utilize homework and teacher knowledge of formative assessment practice. The results could also be used as a base for designing professional development programs by giving school leaders information on organizational analysis, leadership theory, and adult learning theory concepts important to learning experiences.

\section{Rationale for Qualitative Study}

Social science research consists of three approaches, each with a unique set of assumptions which drive its design. Careful consideration of the philosophical assumptions, the purpose of the research, and the intended use of the information generated all form the basis of a sound research proposal. Crotty (1998) suggested four questions should be considered when designing a research proposal:

1. What epistemology informs the research?

2. What theoretical perspective frames the methodology in question?

3. What methodology governs the choice and use of methods?

4. What methods are appropriate to propose to use?

These four questions demonstrate the interrelated levels of decisions making up part of the research design process (Creswell, 2003).

An individual who develops research proposals should understand the philosophy of science which has produced methodological principles of sound research design (Coghlan \& 
Brannick, 2005). Epistemology, ontology, and systematic reflexivity are philosophical principles that help researchers to legitimize their own distinctive way of doing research and determine what they consider as valid, justifiable contributions to knowledge and theory (Coghlan \& Brannick, 2005). Epistemology has two forms, objectivist and subjectivist. Objectivist epistemology views the world in theory-neutral language where the external world can be accessed objectively. Subjectivist epistemology denies this possibility of theory-neutral language.

This same dichotomy exists with ontology as well. Ontology is the nature of the world and can be seen through either subjectivist or objectivist lenses. Subjective ontology assumes reality is a product of the output of human cognitive processes whereas objectivist ontology assumes social and natural reality exists independently prior to human cognition. Reflexivity involves reflection on the relationship between the researcher and the object of research. Coghlan and Brannick (2005) defined systematic reflexivity as, “...the constant analysis of one's own theoretical and methodological presuppositions which helps with retaining an awareness of the importance of other people's definitions and understandings of theirs" (p. 6).

Qualitative research operates on the set of underlying epistemological, ontological, and theoretical assumptions grounded in the hermeneutic tradition. Qualitative research espouses there is no objective or single knowable external reality, rather reality is constructed by individuals within their social worlds (Coghlan \& Brannick, 2005). This position is subjectivist in both ontology and epistemology, along with being inherently value-laden. Herr and Anderson (2005) pointed out the differing types of positionality within the context of qualitative or participatory action research, all of which involve a level of collaboration 
among researcher and setting. The collaborative construction of the reality present within the research setting and the researcher as an integral part of the research process, not separate from it, allow qualitative research to reveal a rich description of the problem (Coghlan \& Brannick, 2005).

In order to provide this rich description, qualitative research employs a variety of data collections methods to assist in the development of a descriptive understanding of the phenomena examined in the study. Focus groups, document analysis, open-ended surveys, and field notes are an example of some of the data collection tools used in qualitative research (Creswell, 2003; Merriam, 1998). The use of descriptive data explains the reasons for the appearance of qualitative research as broad and panoramic rather than microanalyses of particular phenomena. A complex and interactive narrative which emerges through codes, themes, and finally interpretation allows a qualitative researcher to learn from the participants in the study (Creswell, 2003).

Qualitative researchers use reasoning which is largely inductive, however the nature of qualitative research demands the use of deductive reasoning as well. This interplay of inductive and deductive reasoning creates a complex web which is multifaceted, iterative, and simultaneous in nature (Creswell, 2003). Data collection methods must reflect this complexity if a researcher is to attain the essence of qualitative research and reveal the understanding of reality of individuals in their social worlds (Merriam, 1998). More importantly, data collection protocols developed prior to the study help a researcher ensure the final description fulfills the purpose of making sense how others view the world around them. 
For the purpose of this research project, the researcher will employ a phenomenological strategy of inquiry. Patton (1990) noted this type of research is based on, "The assumption that there is an essence or essences to shared experience. These essences are the core meanings mutually understood through a phenomenon commonly experienced" (p. 70). Homework practice is embedded in the shared experience of educators both as students and teachers. Homework as a phenomena based on this shared experience makes a qualitative research approach plausible.

\section{Research Questions}

Within the framework of this study, the following research questions were proposed:

1. What are teacher assumptions of the purpose of homework as a classroom assessment tool?

2. What are the uses of homework as a part of current classroom assessment practice?

3. What are current teacher understandings of homework as a formative assessment tool?

\section{Participants}

The goal of qualitative research is to rely as much as possible on the participants' views of the situation to be studied (Creswell, 2003). Qualitative research assumptions hold that individuals seek understanding of the world around them through subjective interpretations of the meaning of their experiences. For phenomenological research strategy, a purposeful sample selection will add to the understanding of the phenomena to be studied. 
Patton (1990) stated:

The logic and power of purposeful sampling lies in selecting information-rich cases for study in depth. Information-rich cases are those from which one can learn a great deal about issues of central importance to the purpose of the research, thus the term purposeful sampling. (p. 169)

The participants in this study were selected from Midwestern high schools. Participants in the study were given anonymity through the use of pseudonyms for both their name and location. Since the sample was selected purposely to help the researcher understand the problem the number of participants was not an overriding concern. For the purpose of this study, three teacher focus groups from three separate public school institutions in a Midwestern state as well as all teachers in three separate public school institutions were asked to participate. Teachers were selected due to their knowledge of the phenomena selected for this study.

The researcher used the following data collection methods recommended by Merriam (1998): three teacher focus group interviews with approximately 6-8 participants in each group from three different secondary schools; interviews of 50 teachers from three different secondary schools through an online, open-ended survey; and document analysis of twelve teacher syllabi from various content areas. The online interview, focus groups, and written document analysis were conducted in the fall of 2010. Additionally, reflective notes were taken by the researcher to help bring integrity to the research project. Critical reflection within the one's mind is an important concept of adult learning theory (Mezirow, 2000) and provided insight into the learning occurring during the study.

Before conducting the interviews, the researcher will inform participants of their rights both verbally and in writing. Participants of both teacher focus group interviews and 
teacher online surveys were asked to sign the informed consent letter and were offered the opportunity to voice any questions or concerns about the project with the researcher. The informed consent letters can be found listed as Appendices D and E.

\section{Data Collection}

According to Creswell (2003) qualitative research is interpretive research with the researcher typically involved in a sustained and intensive experience with participants. This places the researcher in the position of being the primary research tool through their processing of the data gathered in the setting (Merriam, 1998). Obtaining the view of reality through the eyes of the participants constructed from their own understanding of the world around them is an essential component of qualitative research. For this study, data was obtained through online interviews, focus group interviews, and document analysis.

In order to gain an understanding of the phenomena studied, interaction with participants is necessary. Broad questions in an interview setting allow a researcher to gain a holistic perspective on the understanding of the participants. These broad questions provide the researcher with complex and encompassing material from which to derive a rich narrative of the phenomena. Interviewing in qualitative research requires questioning skill if a researcher is to understand the context of behavior and a meaning for behavior (Griffee, 2005; Seidman, 1998). Merriam (1998) recommended researchers utilize active listening during the interview process in order to make the respondents comfortable and willing to share in depth answers. Additionally, active listening can allow the researcher to gain a firm understanding of events they themselves have not experienced.

The relational aspect of qualitative research requires the researcher to recognize and monitor their own perspective on the phenomena. Creswell (2003) noted, "The qualitative 
researcher systematically reflects on who he or she is in the inquiry and is sensitive to his or her personal biography and how it shapes the study" (p. 182). Introspection and acknowledgement of values, interests, and biases is critical in understanding the intertwined nature of the personal self and the researcher self. Reflection also provides honesty and openness to the research by recognizing qualitative strategies are inherently value laden (Creswell, 2003).

\section{Focus Groups}

For the purpose of this study, three separate focus groups at three separate secondary public school institutions were conducted with six to ten teachers in each group. A focus group is a special group with a specific process and intent within the framework of the research questions (Kruegar \& Casey, 2000). Focus groups are a useful data collection method for obtaining information about a problem (Patton, 2007). Focus group participants were selected by school size, public or private setting, content area, and invited through a letter sent to the school sites.

\section{Document Analysis}

Creswell (2003) recommended data collection types that go beyond the typical interview or observation to create reader interest and to capture useful information which other methods may miss. Data collection and data analysis are framed by the research questions, therefore to add depth to the study a triangulation of data is necessary. The rationale for document analysis is to support and enrich the description of participant understanding of the phenomena being examined. The documents analyzed were teacher syllabi from a various courses found in the secondary school setting. All documents were archival data obtained from the researcher's work site. 


\section{Interview Protocol}

Qualitative researchers often engage multiple data collection methods each of which require a protocol. Creswell (2003) noted interview protocol includes the following components: a heading, instructions to the interviewer, the key research questions, probes for expanding on key questions, transition messages for the interviewer, space for recording responses, and space for the researcher to document reflective notes. Interviews can take on several formats, but Merriam (1998) suggested a semi structured approach to asking questions creates comparable data among participants. For the purpose of this study, the researcher used an interview guide in order to keep questions consistent and to create uniformity among the focus group interviews. All interview questions are aligned to the research questions and the purpose of the study.

\section{Ethical Consideration}

According to Merriam (1998),

In qualitative studies, ethical dilemmas are likely to emerge with regard to the collection of data and in the dissemination of findings. Overlaying both the collection of data and the dissemination of findings is the researcher-participant relationship. (p.

The unique feature of researcher as the instrument of data collection and interpreter of the data can threaten the trustworthiness of the research findings. Interestingly, there is some debate about what constitutes validity and reliability, the constructs of trustworthiness, in a qualitative research project. The argument has been made that qualitative research, which is based on a different set of assumptions about reality, should consider validity and reliability from the perspective of the philosophical assumptions of the paradigm (Merriam, 1998). 
Lincoln (1995) proposed the criteria for quality in interpretive inquiry be based on the relational aspects of the research project, the knower and the known being an example. Therefore, it is recommended qualitative researchers use a triangulation of data to bolster these relational aspects with data gathered outside of interview or observation.

Prior to conducting research, the researcher submitted a research plan to the University of Missouri-Columbia Institutional Review Board. The plan was comprised of a description of the study and a strategy for distribution of the findings. An informed consent letter, a letter to the data gatekeeper for each secondary school, and a description of the interview process were sent to participating individuals and schools.

\section{Biases}

Creswell (2003) warned qualitative researchers over the concerns inherent to the genre and recommended the identification of their biases, values, and personal issues. The closeness of the researcher to the topic and the participants makes bias a legitimate concern due to nature of the researcher's construction of reality. By identifying the aforementioned issues, articulating them in the assumptions and theory behind the research, and understanding the researcher position in the project, a researcher can account for their biases. Validity

In qualitative research, validity does not carry the same meaning as it does in quantitative research and it is not a companion of reliability either (Creswell, 2003). Validity is a strength of qualitative research, but it is used to determine whether the findings are accurate from the standpoint of the participant, the researcher, or the readers of an account (Creswell \& Miller, 2000). To enhance the validity, a researcher can employ three important strategies; triangulation of different data sources, member-checking which involves dialoging 
with participants about the final report, and the use of rich, thick description to convey findings. These validity strategies need to provide enough quality to the study to bring clarity to the findings.

\section{Reliability}

In describing reliability in qualitative studies, Merriam (1998) noted, "Reliability is problematic in the social sciences simply because human behavior is never static" (p. 205). Qualitative research is not conducted to isolate human behavior; instead it is designed to seek, describe, and explain the world as those in the world through their experiences. Bednarz (1985) stated,

If the researcher's self is the prime instrument of inquiry, and the self-in-the-world is the best source of knowledge about the social world, and social reality is held to be an emergent property of interacting selves, and the meanings people live by are malleable as a basic feature of social life, the concern over reliability-in the postpositivist sense- is fanciful. (p. 303)

Reliability in the qualitative paradigm is more concerned about dependability or consistency of the results and that the results make sense to the reader.

\section{Data Analysis}

According to Merriam (1998), data analysis is one of the few facets of qualitative research is which there is a wrong way and a right way. Merriam (1998) recommended analyzing the data simultaneously with the data collection. As stated earlier, the immersion of the researcher into the setting and their role as the primary data collector makes this simultaneous analyzation possible. Additionally, without a continuous, ongoing analysis of the data the emergent aspect of qualitative research can create unfocused and overwhelming 
amounts of data to be processed (Merriam, 1998). Creswell (2003) offered what is termed as generic steps to follow when analyzing qualitative data:

1. Organize and prepare the data for analysis.

2. Read through all the data.

3. Begin a detailed analysis with a coding process which organizes material into chunks.

4. Use the coding process to generate a description of the setting or people as well as categories or themes for analysis.

The researcher will use the aforementioned guidelines for developing a protocol to analyze the data collected. All focus groups interviews will be analyzed simultaneously during the interview through the use of researcher notes, interviews will be transcribed as well. Each focus group interview transcription will be read and reread to assist in the development of codes and themes. Codes and themes will be put into chunks for categorization and analysis to determine if further categories are needed (Creswell, 2003). Constant and critical reflection upon the data will be employed to ensure categories match the topic and research phenomena.

\section{Summary}

Chapter Three contained the research questions as well as the qualitative strategies that shape the design of the study. Three measures; teacher focus group interviews, teacher online open-ended questionnaire, and teacher syllabi document analysis, were utilized to gather data from multiple sources in an attempt to answer the research questions. Three teacher focus groups from separate public secondary school institutions, course syllabi from secondary teachers of various content areas, and an online open-ended questionnaire were 
used to gather data. Qualitative research methodology to address validity, reliability, and ethical considerations were also presented. The emergent themes from the data will be discussed on Chapter Four. Chapter Five includes the results of the findings as well as suggestions for future research. 


\section{CHAPTER FOUR \\ DISCUSSION OF FINDINGS}

\section{Introduction}

Contained in Chapter Four are the results of this study, which was conducted in order to gain an understanding of teacher assumptions regarding homework as a classroom assessment tool, the uses of homework as part of current classroom assessment, and teacher knowledge of homework as formative assessment through a qualitative study of three Midwestern high schools. An online open-ended survey, focus group interviews, and document analysis were used to investigate the assumptions, purpose, and use of homework as well as teacher knowledge of homework as formative assessment.

Teacher participants were questioned about their perceptions of homework as a learning tool, their purpose for homework as an assessment tool, and their use of homework as a classroom assessment tool. Data gathered from both the online survey and focus group interviews were noted and analyzed for emergent themes. Document analysis in the form of course syllabi provided additional data to facilitate a better understanding of how teachers are applying homework in the classroom and their assessment practices associated with homework. Themes that emerged through the data were analyzed through the lens of research based homework practices and formative assessment concepts. In addition, leadership theory and adult learning theory were utilized in the data analysis in order to provide educational leaders with knowledge of teacher expectations as it pertains to professional development.

Chapter Four is divided into four sections. A description of the data collection process, including the setting, participants, and observations, followed by a statement of the researcher's professional background and potential biases brought to the study makeup those 
four sections. Data analysis is discussed as it relates to the three research questions, followed by the conclusion of the chapter. The three research questions proposed for this study were;

Three research questions were proposed for purpose of this project:

1. What are teacher assumptions of the purpose of homework as a classroom assessment tool?

2. What are the uses of homework as a part of current classroom assessment practice?

3. What are current teacher understandings of homework as a formative assessment tool?

\section{Data Collection}

Data for this study were collected by conducting focus group interviews and an online, open-ended survey with public and private school teachers. Interview data was collected by conducting three focus group sessions involving the faculty members of three high schools in the Midwest. Additionally, documents in the form of course syllabi were also analyzed for information about teacher classroom assessment procedures.

\section{Setting}

Three high schools were selected for this study. School A (SA) is located in an urban area, within one of the largest cities in the southwestern part of a Midwestern state. School A (SA) is a mid-sized private high school, has a student population of almost 350 , and 30 full time faculty members. SA is also one of a small number of private schools in this area. SA has an administrative team comprised of one principal and one activity director. SA's demographic profile shows a student population that is $97 \%$ white, $3 \%$ other ethnicities, no identifiable special needs population, and no identifiable low income population. The lack of 
information on special needs and low income students is due to the fact that this institution does not maintain records of this nature. SA has an average American College Test (ACT) score of 24 which is well above the national average of 21.1.

School B (SB) is located in a small suburban city approximately 20 miles from one of the largest cities in the southwestern part of a Midwestern state. School B (SB) is a public high with approximately 700 students and 50 faculty members. School B has an administrative team comprised of one principal, one assistant principal, and one activities director. SB's demographic profile shows a student population that is $97 \%$ white, $3 \%$ other ethnicities, a free and reduced lunch rate in the $20-30 \%$ range, and $8 \%$ of the student population has been identified as special needs. End of Course exam data reveals SB has met Adequate Yearly Progress (AYP), as set forth by No Child Left Behind (NCLB), in both communication arts and mathematics for all demographic subgroups. ACT data revealed in 2010 SB performed above the national average of 21.1 with an average student score of 22.

School C (SC) is located in a small suburban city approximately 15 miles from one of the largest cities in the southwestern part of a Midwestern state. School C (SC) is a large public high school with a student population of nearly 1400 and 85 fulltime faculty members. School C has one principal, three assistant principals, and one activities director. SC's demographic profile show a student population that is $97 \%$ white, $3 \%$ other ethnicities, a free and reduced lunch rate in the $40-50 \%$ range, and $10 \%$ of the student population has been identified as special needs. End of Course exam data reveals SC has met AYP requirements in the area of communication arts. SC did not meet AYP in the area of mathematics due to low performance by the special needs subgroup. ACT data for 2010 revealed SC performed above the national average of 21.1 with an average student score of 21.5. 


\section{Focus Group Interview Participants}

The primary sources of data collection came from focus group interviews and online, open-ended surveys with teachers from each of the selected high schools. There were six focus group interview participants at each of the three selected school sites. These individuals were purposefully selected because of their position as a current classroom teacher in the secondary school setting. The Principals of each school were initially contacted by the researcher. Approximately one week later, the researcher followed up with an additional phone call to the Principals to confirm their support for the research project and to finalize details of the actual research. Additionally, permission was also sought from the Principals who agreed to allow focus group interviews and online, open-ended surveys involving their faculty at their school site. Each of the Principals signed a letter of support for the focus group interviews and online open-ended surveys and encouraged their faculty to participate with the research project.

Teacher participation was based on employment as a secondary school instructor. Participants represented various levels of experience and content areas found within the faculty of each school site. The interviews were conducted in a location selected by the participants. Interviews took place in a classroom, a media center, and a faculty work room. All interviews were tape recorded and transcribed. Pseudonyms were developed to protect the identity of participating schools and individuals. The faculty members were purposefully selected in order to represent a variety of years of experience, subject areas, and grade levels. Table 1 shows the data of the individuals who participated in the focus group interviews. The focus group interview protocol can be found in Appendix A. One faculty focus group 
session was held at SA, SB, and SC. Each focus group session lasted approximately 90 minutes and consisted of six purposefully selected faculty members.

\section{Online, Open-Ended Survey}

The researcher utilized an online, open-ended survey sent to each of the participating schools SA, SB, and SC. The survey was sent to the building principal for distribution to the faculty after the focus group interview participants had been selected. Focus groups participants were asked by the researcher to not participate in the survey as the general course of questions were the same between the focus group interview protocol and survey protocol.

Each potential participant was sent an e-mail detailing the study and the intent of the survey. Two attachments were sent with the e-mail. One attachment contained the permission letter from the building principal which granted research permission. The other attachment was an informed consent letter which detailed the rights of an individual as a research participant. The online, open-ended survey can be found in Appendix B. Forty individuals completed the survey out of potential sample of 140 participants. School A had 17 participants, School B had 13 participants, and School C had 10 participants. Participants will be identified by their response number and school letter. For example, a survey participant from School A who was the $13^{\text {th }}$ respondent to the survey will be referred to in the text as survey participant $13 \mathrm{~A}$.

\section{Document Analysis}

The researcher asked 15 teachers from various content areas for permission to study course syllabi that had distributed to students at the beginning of the course. All documents provided had the descriptions of the course and expectations for student work clearly 
Table 1

Identifying Codes and Demographics of Focus Group Participants

\begin{tabular}{|c|c|c|c|c|}
\hline ID & Gender & Years of Experience & Grade Level & Subject \\
\hline SAT1 & Female & 4 & $11-12$ & Science \\
\hline SAT2 & Female & 6 & $10-12$ & Math \\
\hline SAT3 & Female & 2 & $9-12$ & Science \\
\hline SAT4 & Female & 10 & $9-12$ & Math \\
\hline SAT5 & Male & 15 & 11 & American History \\
\hline SAT6 & Male & 10 & $10-11$ & Communication Arts \\
\hline SBT1 & Female & 10 & $9-10$ & Communication Arts \\
\hline SBT2 & Female & 17 & $11-12$ & Communication Arts \\
\hline SBT3 & Female & 2 & $9-10$ & Communication Arts \\
\hline SBT4 & Male & 25 & 9 & American History \\
\hline SBT5 & Female & 14 & $9-12$ & Family/Consumer Sciences \\
\hline SBT6 & Male & 13 & $10-12$ & Social Studies \\
\hline SCT1 & Female & 17 & $11-12$ & Math \\
\hline $\mathrm{SCT} 2$ & Male & 29 & $11-12$ & Science \\
\hline SCT3 & Female & 15 & $11-12$ & Communication Arts \\
\hline SCT4 & Female & 20 & $9-11$ & Math \\
\hline SCT5 & Female & 15 & $9-11$ & Communication Arts \\
\hline SCT6 & Male & 12 & $11-12$ & Social Studies \\
\hline
\end{tabular}

Note. SAT $=$ School A; $\mathrm{SBT}=$ School $\mathrm{B} ; \mathrm{SCT}=$ School $\mathrm{C} ; \mathrm{T}=$ Teacher. 
explained. Key items of the syllabi directly relating to student work were entered into a document analysis sheet which can be found in Appendix C. As suggested by Creswell (2003), these items were reviewed, studied multiple times, and coded for themes. General themes began emerge, the themes were analyzed, and are discussed in this chapter.

\section{Researcher Background and Bias}

\section{Researcher Background}

The researcher holds a Masters degree in Secondary Education. He has obtained secondary school administration licensure through a combination of educational administration courses and a passing score on the ISLLC exam. He has taught for 13 years in public schools in the Midwest and has experience teaching K-12 students in several content areas. The researcher has served as a high school administrator in a public school in the Midwest, both as an assistant principal and as a principal. Additionally, he has 20 years of coaching experience in which he worked with young athletes ranging from seventh grade to twelfth grade and fellow coaches in the area of program development. As an administrator in public school, the researcher has experience with curriculum development, supervising teachers, facility maintenance, discipline, budgeting, program development and implementation, policy development, professional development, and working with the school board for purpose of school improvement.

\section{Researcher Bias}

The researcher brought three biases to the research and process of analysis of the data. First, the researcher was influenced by personal educational experiences within public schools. The researcher was educated in public schools and currently works as an administrator for a public school. Secondly, the researcher has an extensive background in 
the elementary setting prior to entry into secondary administration. The expectations and treatment of children in the elementary setting predisposed the researcher to view all students as children not a adults as often found in secondary school. Lastly, intense personal learning in the area of assessment has created a viewpoint within the researcher that a change in assessment practices, in particular homework, is necessary to improve student achievement.

The researcher worked in two ways to bind the effects of his personal biases due to these experiences. One was to recognize these biases going into the study and throughout the data collection process. The researcher asked questions such as; "What is going on in this data collection process? What am I hearing and how am I learning from this information? How are my previous experiences influencing my survey analysis and focus groups? Are their questions that I should be asking of myself to help reflect and interpret the data accurately?" Along with these questions, the researcher engaged in active listening during focus group interview sessions as a method to reduce potential bias (Bogdan \& Bilken, 1998).

To minimize bias and enhance the credibility and rigor of the project, the researcher used a member checking technique by providing the themes gleaned from the transcriptions to each participant (Rossman \& Rallis, 1998). A second method utilized to enhance the validity of the study was peer debriefing. Creswell (2003) described peer debriefing as, “...locating a person who reviews and asks questions about the qualitative study so that the account will resonate with people other than the researcher" (p. 196). The researcher provided the data to two separate education professionals for their review prior to writing a formal analysis. 


\section{Data Analysis}

The focus group interview sessions lasted approximately 90 minutes and all of the sessions were audio-taped. Immediately following each focus group interview, the researcher listened to an audio recording of the sessions. Initial thoughts were jotted down as some similarities seemed to reoccur with each focus group. After listening to the recordings, the researcher then began the process of transcribing the interviews, again writing down thoughts as the transcription process unfolded. The researcher also reread the transcriptions and notes in order to gain a general understanding of the information (Creswell, 2003). After several readings of the data general themes began to emerge. Ideas were placed in the margins of the transcripts, common threads and themes were highlighted and color coded.

The same process was undertaken to analyze the online open-ended survey minus the listening portion. The survey was designed to mirror the focus group interview process, but in a manner which elicited more participants. Survey results provided a transcript for the researcher to analyze and code for themes in much the same manner as the focus group interviews. Similar ideas and thoughts were identified as themes began to emerge from this set of data. The researcher spent time reflecting after reading both sets of transcripts as well as repeatedly listening to the audio recordings to deepen understanding of the data.

Additionally, data from the document analysis portion of the research was infused into the reflective thinking of the researcher. Themes emerged from this data which seemed incongruent when compared with the data from the survey and interviews.

Upon continued study, emergent themes were developed into the following major categories that addressed each of the research questions: teacher perception of the purpose of homework, the uses of homework as part of classroom assessment practice, and teacher 
understanding of homework as a formative assessment tool. Each of these categories had several sub-themes emerge within them. The remainder of this chapter addresses the three research questions in relation to the emergent categories and sub-themes. Data collected from the interview, survey, and document analysis are used to explain and support the findings related to each research question.

\section{Teacher Perception of the Purpose of Homework}

The information gathered in this category provided answers as to how teachers perceive the purpose of homework as a classroom assessment practice. The sub categories which emerged were Traditional Practice, Extension of Class Time, Practice, and Student Accountability. These sub categories are arranged from most prevalent to least prevalent.

\section{Traditional Practice}

The most dominant theme that emerged from an analysis of the data of the transcripts was teachers gained their perceptions of homework from past experience. A large number of teachers expressed their perception of homework was shaped by experiences as a student, from learning from other teachers, or what they believe to work. Survey participant A16 stated, "My own experiences in school and what I think over the years has worked best for my students." SAT1 noted, "Student experiences is the number one way I learned about homework." Another teacher, SBT3 responded, "My mentor and I had an understanding by design curriculum class in college. Graduate work talked a lot about testing in that some tests don't give you what you want from students." Survey participant A14 wrote, "Modeling after classroom teachers I student taught with, philosophy of education in college, and expectations from administrators have all shaped my current use of assessment." Extension of Class Time 
A theme that emerged from several responses in the interview transcripts was the perception homework is utilized as an extension of class time. On numerous occasions teachers stated they perceived homework as a method to increase the amount of time students are exposed to the content or processing content. As an example, survey participant 10C stated, "As a history teacher I believed and still believe it (homework) was a means to an end. Not the only means but one exposure of many to assist the learning process." Contained within this category are the two sub categories of Reading, and What Can't Be Completed In Class. Each of these categories is discussed in the following sections and arranged in order of their prevalence in the transcripts.

Reading. Many respondents noted their perception of the use of homework was to allow students the opportunity to read material pertinent to the course, but which could not be completed during school hours. SAT2 stated:

I think reading is very important in the homework process it helps them (students) practice and reiterate the important things especially if they know what the quizzes are about and it really has to do with homework letting them work on their own. Similarly SAT1 noted:

I feel like it is practice especially in physics there is a lot of math stuff they have to practice to learn or to be able to understand. Then in AP courses there is a lot of reading and self assessment.

SBT3, a communication arts teacher, stated:

There is not a lot of like I am going to hand you this paper you go home do this and bring it back tomorrow. There are things they need to do outside the classroom, like 
reading for example, they can't do here. I don't call it homework and I am hoping it prepares them for something next.

According to another teacher SCT3:

The literature readings I have students engage require they spend time reading outside of class in order for them to participate fully in discussions. It is impossible for us as a class to read an entire novel start to finish in class and cover the other material required for me to complete in a school year. Students must take the time to read chapters from the books and summarize these so that they can come to my class ready to discuss the major portions of the book and how it relates to the parts of story development.

The importance of reading was also found in the document analysis portion of the data. Two teachers, both science teachers, emphasized all assignments would be completed in class with the exception of reading. Students would be expected to complete all course readings outside of the classroom setting.

What Can't be Completed in Class. A number of teachers in both the interview and survey data indicated homework was utilized for work that could not be completed in class. Survey participant 1A stated, "I rarely use it. The majority of the time I will only give homework if a student needs more time to complete an in class assignment." Survey participant 3B noted, "I do not really use homework as an assessment tool. The only time I have used homework so far is if a student does not finish an assignment in the allotted time that was given in class." SBT3 stated: 
I pick homework in hopes it extends learning as an example, while their reading I have them take notes then outside of class they write a summary of those notes. So this becomes my assessment and grade for that time instead of a quiz.

Survey participant 14A stated, "Any homework assigned to students is based on not getting it done while in a classroom setting." SCT3 responded, "The purpose of my current use of homework is to finish assignments that students could not finish in class."

\section{Practice}

Practice of key course concepts emerged from the interview and survey data analysis with several teachers stating the importance of practicing outside of class time. Teachers appear to perceive this to be a very important use of homework. Survey participant 13B stated,

In the subject of math, I feel like students have to repeat the process in order to understand. Some need more repetition; some need less; so homework is a way I try to ensure they get the repetition they need.

Survey participant $16 \mathrm{~A}$ noted, "The purpose of homework is to reinforce students learning and to enhance opportunities beyond the textbook material." SAT3 responded:

I know a lot of people in math say they hate the homework because it is so long and I have always struggled with that so I always hated homework because I understood it in class. So doing repetitive homework did not seem like it had a purpose to me so right now the purpose is just practice.

SCT5 stated, "I give students work I feel will help them to practice and better understand the concepts in my class. It is my experience that when students practice they improve their learning." Survey participant $2 \mathrm{C}$ stated, "Homework would be used as practice, rather than 
for a grade. Students complete homework through their own volition, or if they get behind in class, they might work outside of the time period to catch themselves up."

An important aspect of the practice theme emerged from analyzing this portion of the data that was not separated as sub categories. Several respondents indicated their perception of homework was as a form of guided practice. This misconception is an indication that there is an apparent disconnect in the understanding of guided practice versus independent practice. An example of this misconception can be found in survey participant 9A's response, “The purpose of my homework is as guided practice to determine a student's understanding of course objectives." Additionally, survey participant 14B stated, "My students complete guided practice assignments individually."

Guided practice involves either teacher or peer guidance during the practice phase and corrections to student misunderstanding takes place during the instructional time period (Marzano, Pickering, \& Pollack, 2001). This is not possible if students are completing assignments individually outside of class time instead what students are engaged in is independent practice.

Independent practice is just what it states students do work independently of assistance and receive assistance after the assignment is completed (Marzano et al., 2001). Independent practice is an important tool for student accountability in relation to learning goals and can take place in or out of class time. A prime example of in-class independent practice is assignments to be completed during class time. Homework is an example of independent practice to be completed by the individual student outside of class time. 


\section{Student Accountability}

Throughout the course of interviews, surveys, and in document analysis the concept of student accountability was mentioned many times as an embedded perception of homework. Teachers believe students should be held accountable for performing homework requests. As a result of this belief four sub categories emerged from the data Responsibility, Effort, and Completion of Assignments

Responsibility. Respondents to both focus group interviews and surveys indicated they believed homework was a method to teach not only content, but responsibility. Survey participant C2 stated, "Homework is beneficial when the student makes the decision to work on their learning goals outside of the classroom. This is the only way homework will affect student learning in a positive way." SBT3 stated:

Workshop is built in responsibility because you have to have it in by a certain time. I am going to give you all this feedback along. the way and you will have a good paper which is better for you.

Survey participant A1 noted, "I think that in other areas that are centered around classrooms, homework may be a good method of teaching responsibility or providing repetitions. It is probably not a good method of actually teaching new material."

SCT5 responded:

The purpose of homework is to give enough to see if they are getting the concepts, give it as a way to develop time management skills and responsibility, but not enough assignments that it causes to much stress or burnout in my students.

Similarly, SBT2 responded: 
It is roughly the same idea except in honors I give them a list at the beginning and say these are the things you will complete and it needs to be done this way and it is these types of papers. On some of these we do them in class so I can help them get started then they work on it outside of class and then I give them feedback for revision. It is about them becoming learners and users of information rather than just consumers of information.

Effort. The data which supports this sub category was limited, but insightful from the standpoint the concept of effort was woven into teacher responses. Survey participant C4 noted:

I feel if students saw homework for what it was, a chance to better learn and understand the material, that some of them might do better; however, I don't think most kids care so they see it as busy work and thus it really doesn't affect their learning.

SAT2 stated, "Homework is more practice and they should not get points taken off for practice. Practice should be practice and they should get some credit for really trying to complete the homework right." Survey participant B11 responded, "I give effort grades for participation in class and homework this helps to balance out their grades so their grades are not based solely on effort alone."

Completion of Assignments. A few teachers indicated their desire for students to complete all assignments as a way to improve their learning. An example came from respondent SAT6 who noted: 
I do completion points on whether or not they complete their homework then go over the problems they struggle with and I work as many as I can. They self assess and decide what questions they need to ask me.

SCT2 responded:

I do completion points based on whether or not they complete their homework. I always go over the problems they could not figure out and work as many as I can.

\section{SBT5 stated:}

Well we have to have grades it is an unfortunate evil. You have to $\mathrm{x}$ number of assignments done and if you don't then instead of getting your paper stamped you get $50 \%$ its pretty harsh if you don't do it but the deal is each portfolio check you can improve and help your grade.

Document analysis revealed a number of teachers take a punitive stance toward homework by imposing grade penalties for not completing an assignment. Course syllabi revealed teachers penalize students for incomplete homework assignments ranging from a zero to a reduction of $50 \%$ from the total point value. There were a limited number of cases where students must have all assignments completed before they were allowed to take unit exams. Failure to complete all assignments within a specified time frame could result in a loss of points for both the outstanding homework and the exam.

\section{Summary of Teacher Perceptions of the Purpose of Homework}

The teachers who participated in this study perceived that there were distinct purposes of homework in the classroom. Traditional Practice emerged as the most prevalent theme in relation to how teachers formulate their perception of homework as a part of classroom 
practice. The second most prevalent category of Extended Learning Time emerged which had two sub categories; Reading and What Can't be Completed in Class. Teachers indicated they believe homework was an important way for students to read information pertinent to class outcomes. Additionally, teachers indicated homework was utilized to allow students to complete assignments started in class. Many teachers also indicated from their responses they perceive homework as a form of practice for students. As a result of these responses, Practice emerged as a prevalent theme from the data. Teachers believe in order for students to gain repetitions and master learning outcomes time outside of class was needed practicing these key skills. Interestingly, there appeared to be a misunderstanding of the difference between guided practice and independent practice as a part of lesson design. Teachers indicated they perceived homework, designed to be solo, as guided practice.

Student Accountability was another emergent theme derived from several responses in the data. Contained within this category were the three sub categories of Responsibility, Effort, and Completion of Assignments. Analysis of interview, survey, and document data revealed teachers perceive homework as a tool to teach student accountability. This is instilled through a combination of incentives, in the form of completion points, and punitive measures, in the form of point reduction for failure to complete assignments. See Figure 1 for a graphic representation of the summary of teacher perceptions of homework.

\section{The Uses of Homework as Part of Classroom Assessment Practice}

The focus group interviews, online survey results, and document analysis provided data that gave insight into how teachers use homework as a part of classroom assessment. Through the analysis of transcripts, survey results, and documents three themes on the uses of homework as an assessment tool emerged Checking for Understanding, Grade Balance, 


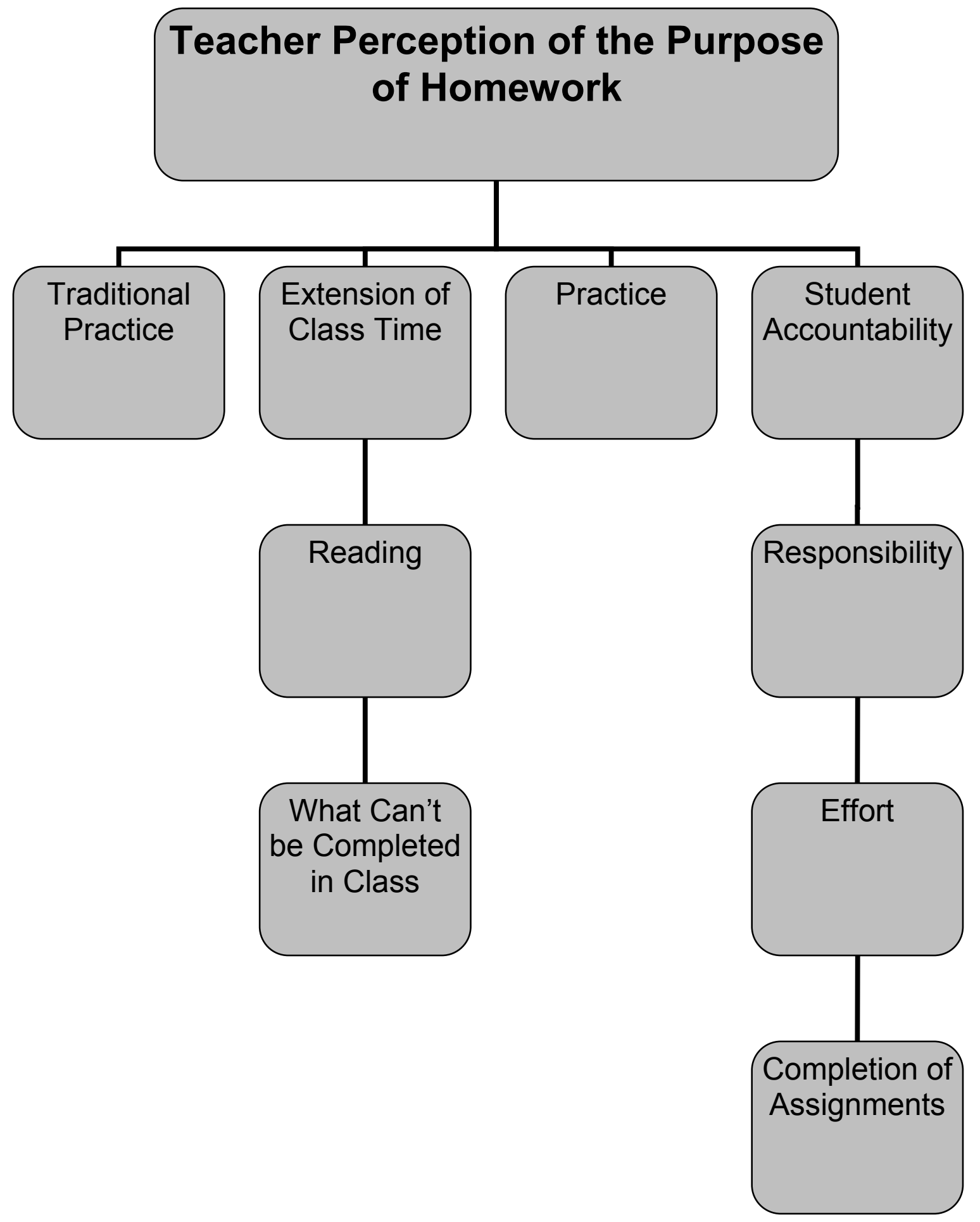

Figure 1. Summary of Teacher Perception of the Purpose of Homework. 
and Grade Generation. These themes are arranged in order of prevalence from most prevalent to least prevalent.

\section{Checking for Understanding}

Several teacher responses indicated one use of homework was to check for student understanding on key concepts. Based on the information teachers receive from homework assignments they adjust instruction. SBT6 stated, "Homework is not primarily for grade generation but rather for allowing kids to see where they are at in the learning process and how to become self regulatory. It also allows me to see what kids are thinking and their level of understanding about concepts." Survey participant C8 noted, "I use homework as an assessment for me. If the kids tried and missed a bunch of points, I take a completion grade for effort. This is a signal I need to regroup and re-teach.” SBT4 stated:

I use homework as preparation for future assignments or what you are planning on doing later in the chapter or what your end goal is and then also just so they can begin to question if they know it and as a teacher if I think I need to re-teach, slowdown or move on.

Survey participant A14 wrote, "The intended is that kids will retain information presented in class by competing additional work at home. In this way, teachers can assess student learning based on the work completed." Additionally survey participant B2:

To show the teacher what was learned the previous day in class. The student returns with a completed homework assignment and therefore the teacher feels as if the objective has been completed.

\section{Grade Balance}


Many teacher responses indicated one use of homework was to provide a buffer for students who performed poorly on tests. Homework provided another way for students to demonstrate mastery of key concepts. SAT1 stated, "Since I have really hard tests the completion points are like a buffer for their grade because if they get a $\mathrm{C}$ on the test then the completion points on homework they can get a B or low A." SCT4 responded, "Homework allows students to show me they know the material. My experience has shown me that some students are not great test takers and so it is not fair to only base grades on tests." Survey participant A9 stated:

I was never a good test taker. Homework kept me from not passing a lot of classes. Based on this experience I decided early on in teaching I was going to provide students with additional time to prove to me they no the content. Homework gives kids a chance to show they know it without all the pressure of a one shot test. Some kids don't turn in homework or score well on tests. That is proof to me homework works as a preparation for tests because my students who do homework usually do well on my tests.

\section{Grade Generation}

Some teacher responses indicated another use of homework was to generate grades. Frequently teachers responded they used homework for grades, but the percentage homework counted toward the final grade was low. However, the document analysis of teacher syllabi revealed some teachers, 5 out of 15 , counted homework as $30 \%$ of a semester grade. A number of teachers believed students should not be held accountable, in the form of grades, for homework due to the intended purpose of practice. SBT3 stated: 
Well we have to have grades; it is an unfortunate evil. You have to $\mathrm{x}$ number of assignments done, and, if you don't, then instead of getting your paper stamped, you get $50 \%$. It is pretty harsh if you don't do it, but the deal is each portfolio check you can improve and help your grade.

SAT2 responded:

Homework is more practice and they should not get points taken off for practice. Practice should be practice and they should get some credit for really trying to complete the homework right. Homework is weighted low for me in my formula of percentages and it is only 10 or 15 points. Tests are where points are taken away because we have practiced and retaught and they have had the opportunity to seek help before the test. I just feel they shouldn't be penalized for practicing.

Survey participant A17 wrote, "Homework is part of the quarter and semester grading factor for the student." Another survey participant, B13 noted, "Students are given an assignment, usually begun in class, and what they do not finish is considered homework. Homework scores are $30 \%$ of their grade."

\section{Summary of the Uses of Homework as Part of Classroom Assessment}

The focus group interviews and survey responses were analyzed. The data revealed three major themes for the uses of homework as classroom assessment Checking for Understanding, Grade Balance, and Grade Generation. These themes are arranged in order of their prevalence in data analysis. Teachers indicated the use of homework is frequent and provides them with a method to assist student learning.

Checking for understanding is a vital part of lesson design and essential for obtaining information on student readiness for summative assessments. A potential problem with 
utilizing homework in this capacity is a teacher does not know if a student actually completed the work returned. SAT3 stated, “...I don't like to use homework as an assessment tool because I see kids in the morning copying each others work. How do I know they completed the assignment?"

Grade balance and grade generation are closely related concepts and were represented with a nearly equal amount of responses, therefore, they will be presented together. Teachers used homework to balance out student grades in case a student did poorly on a test. Interestingly, teachers also used homework to generate grades, but claimed the percentage of the total grade was very low. Survey responses and document analysis indicated in some instances homework counted for $30 \%$ of student grades which is a high percentage. See Figure 2 for a graphic representation of the summary of teacher uses of homework. Teacher Understanding of Homework as a Formative Assessment Tool An analysis of interview transcripts and survey responses revealed teachers have a limited understanding of how to use homework as a formative assessment tool. More importantly, the data revealed teachers have a limited understanding of what formative assessment is and how to use it effectively in classroom practice. Interestingly, survey participants provided much more in depth answers about formative assessment and homework as formative assessment. The predominant themes which emerged were Limited Understanding of Homework as Formative Assessment and Limited Understanding of the Concept of Formative Assessment. The themes are presented in order of their prevalence in data analysis of both interview and survey transcripts. Document analysis revealed a lack of information on formative assessment as it pertains to homework which supports these 


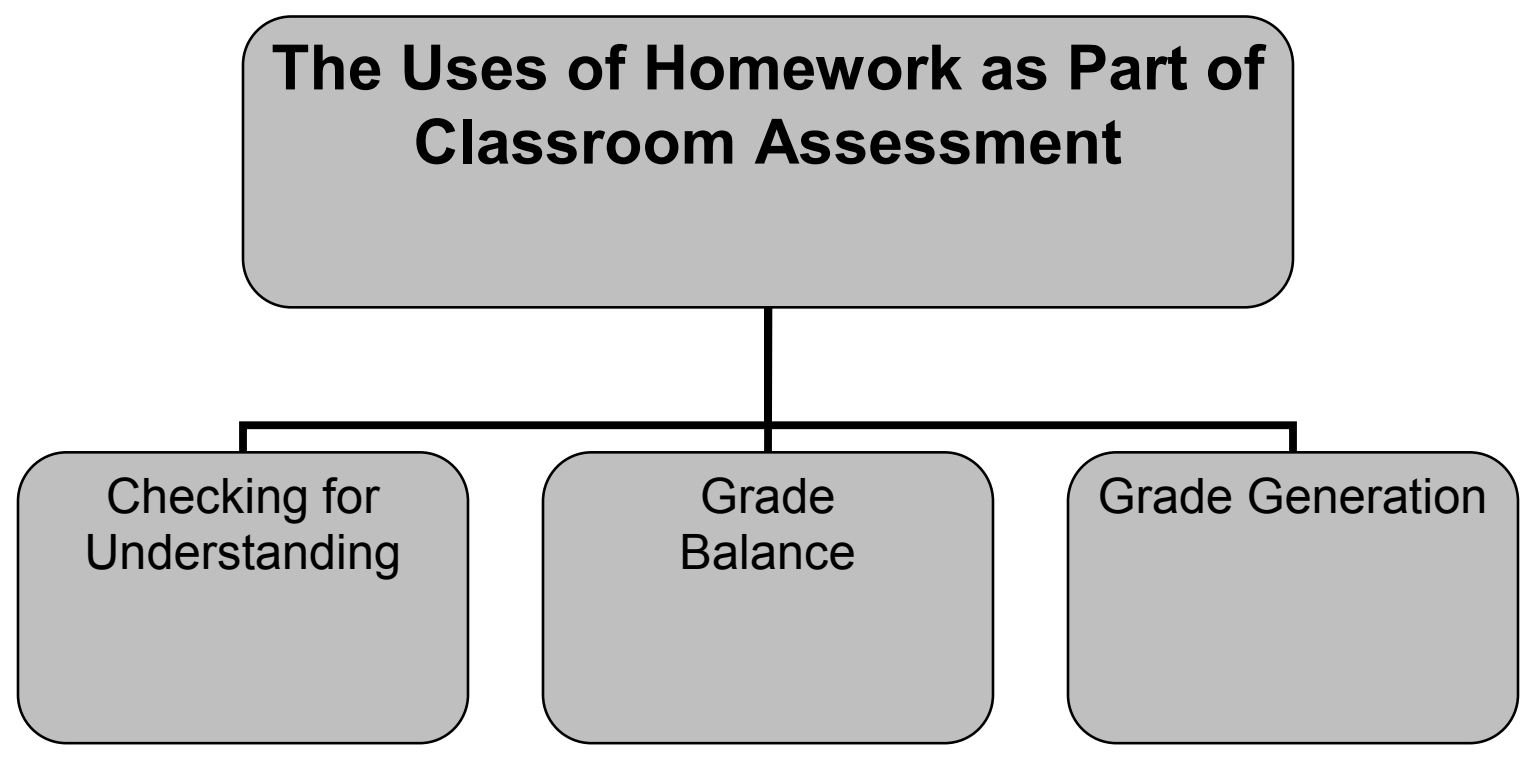

Figure 2. Summary of the Uses of Homework as Part of Classroom Assessment. 
themes. Within this category responses range from a basic knowledge of what formative assessment is to no understanding at all.

\section{Limited Understanding of Homework as Formative Assessment}

All focus group participants at School A stated they had no fundamental knowledge of what formative assessment was or how to apply the concept to homework. School B had only one participant of six which had any knowledge of formative assessment as it applies to homework. This knowledge was a result of work done with a local professional development consortium not associated with the school district in which they were employed, but the training was discontinued after a few sessions due to budget cuts. According to SBT3:

We had just begun to look at how to use formative assessment. I have a fundamental understanding of the concept, but do not use it in my class. Our administrators are going through some kind of assessment training I know, but I am not sure what it is.

Likewise, School C had two participants with knowledge of formative assessment both of which had attended the same local professional development consortium training as the participant in School B.

Survey participants provided, in some instances, expansive answers about their understanding of homework as a formative assessment tool. Unfortunately, the majority of these answers were missing essential components of formative assessment. Survey participant A6 stated, "I make sure I have discussed the info before we grade the homework." Survey participant B10 wrote, "I use a point system to evaluate and make correction to students work." Another survey participant, C9, stated, "I see how students did on the assignments, I answer questions on it, I provide help if they ask, and give feedback to help them learn." 


\section{Limited Understanding of the Concept of Formative Assessment}

As found in the previous section, focus group participants stated they had little to no understanding of formative assessment. SAT1 stated, “Isn’t formative assessment like quizzes and labs and summative assessments are like tests?" SCT5 noted, "I believe formative assessment is pre-test and post-test data to help me see if kids have progressed toward the learning goal." Survey participant A 17 wrote, "Assessment for learning must mean homework and formative is classroom work?"

A few teachers demonstrated a basic understanding of the concept, but their understanding appears limited to how to adjust their teaching. As discussed in the literature review, a major component to formative assessment is to enhance the student's ability to monitor and adjust their learning. Examples of this basic knowledge are found in the following quotes. Survey participant A2 stated:

Formative assessment helps me regulate what needs to be taught, it helps the student regulate what they want, and need to learn in order to achieve their goal. To me, largely reflective in nature and it drives the instruction, moving the learning forward at a constant pace with self reflection at various times.

Survey participant B12 wrote:

I think formative assessment is recognizing what your students are/aren't learning. It is interaction between me and my students to help me understand how to teach them better. In fact, I think homework is a form of formative assessment for me because I can see who did or did not understand, who didn't, and what I need to make sure to go over. 
Survey participant C4 noted, "FA (formative assessment) is a two-way street between student and teacher. Formative assessment is a means to enhance student learning. Summative assessment is a means to assign a student a grade."

These quotes all provide solid evidence that some teachers do understand a portion of formative assessment. More importantly, these responses lack a key component of formative assessment which is promoting self-efficacy and metacognitive skills in students. Data gleaned from interviews and survey respondents point to teachers using formative assessment primarily to monitor and adjust their instruction.

\section{Summary of Teacher Understanding of Homework as a Formative Assessment Tool}

The data obtained in this study revealed teachers have a limited knowledge of both formative assessment and homework as a formative assessment tool. Two major themes emerged from the data Limited Understanding of Homework as Formative Assessment and Limited Understanding of the Concept of Formative Assessment. Responses consistently pointed to a lack of understanding or an understanding which is limited to how formative assessment can impact teaching. Additionally, document analysis revealed no description of homework as formative assessment. See Figure 3 for a graphic representation of the summary of teacher understanding of homework as formative assessment.

\section{Summary}

In Chapter Four, a description of how data were collected and analyzed in this project was detailed. The background and biases the researcher brought to the data collection and analyzation process were described. Three major themes and categories emerged as a result of the data analysis: teacher perception of the purpose of homework, teacher use of homework in classroom assessment practice, and teacher understanding of homework as a 


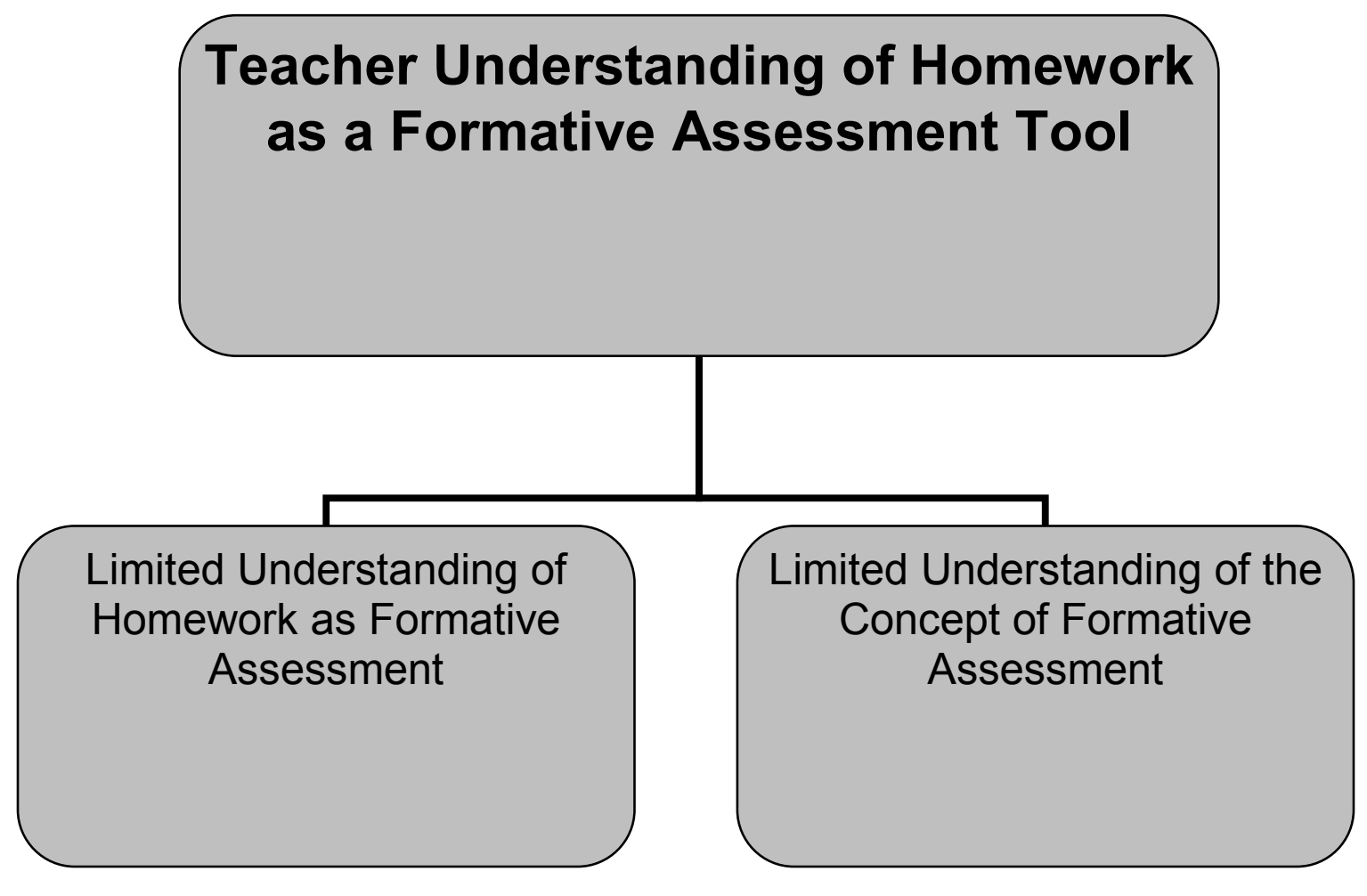

Figure 3. Summary of Teacher Understanding of Homework as a Formative Assessment Tool. 
formative assessment tool. Within each major category emerged a number of sub-themes which addressed the three research questions. The categories help to provide a description of the nature of teacher practices in the area of homework. See Figure 4 for a graphic summary of the findings in Chapter Four. Contained in Chapter five is a broad review of the study and the findings as they relate to the research questions. Limitations of the study are reviewed and implications for public school leaders are provided. Additionally, implications for future research are discussed and proposed. 


\section{Teacher Perception of the \\ Purpose of Homework}

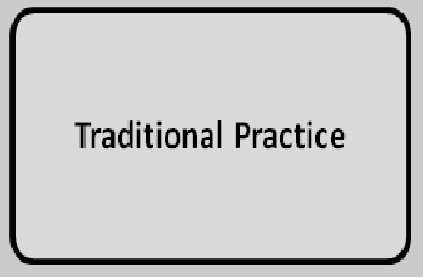

\section{Extension of Class Time \\ - Reading \\ - What Can't be Completed in Class}

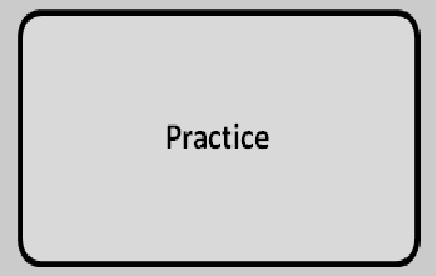

Student Accountability

- Responsibility

- Effort

- Completion of Assignment
The Uses of Homework as

Part of Classroom

Assessement
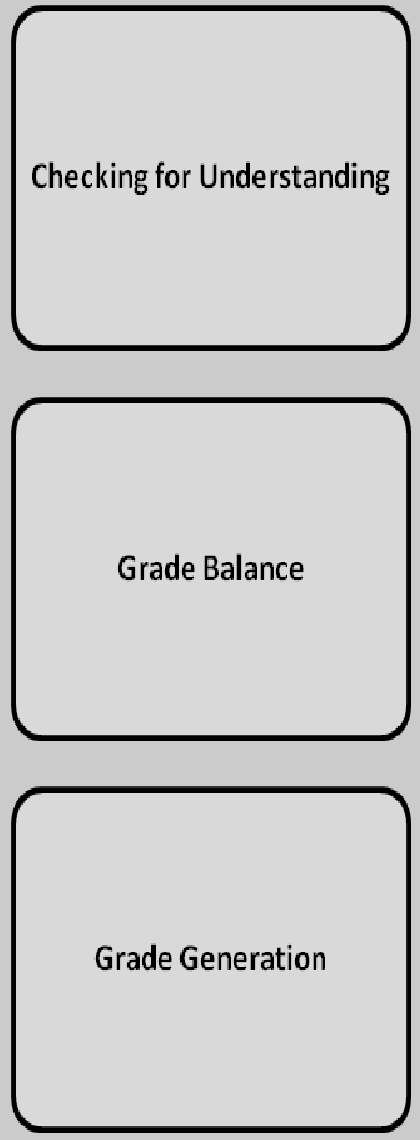

Teacher Understanding of Homework as a Formative Assessment Tool

Limited Understanding of Homework as Formative Assessment

Limited Understanding of the Concept Formative Assessment

Figure 4. Summary of Findings. 


\section{CHAPTER FIVE \\ DISCUSSION OF RESULTS}

\section{Introduction}

In this chapter, conclusions are drawn from this study's findings in reference to previous studies of formative assessment practices in the classroom and the use of homework as an assessment tool in classroom practice. The discussion centers on the interpretation of previous studies of formative assessment (Black et al, 2004; Black \& Wiliam, 1998; Moss \& Brookhart, 2009) and the use of homework as classroom assessment (Kohn, 2006; Vatterott, 2009). Additionally, aspects of grading practices (Dweck, 2007; Kohn, 2006; Guskey, 2004a, 2004b, 2009; Guskey \& Anderman, 2008; Guskey \& Bailey, 2001) are also discussed as they relate to motivation, homework and formative assessment. This study used qualitative research methods to examine how secondary teachers perceive the use of homework in classroom assessment practice, how secondary teachers use homework as a part of classroom assessment, and teacher understanding of homework as a formative assessment tool. The themes that emerged from the analysis of this study's data support many findings of previous studies described in Chapter Two. The data indicated that the assertions of previous research into formative assessment and homework are all still pervasive in the secondary classroom of today.

\section{Purpose of the Study}

The purpose of this study was to improve the understanding of homework as a formative assessment tool in the secondary classroom through a qualitative study of how secondary teachers perceive, use, and understand both concepts. An extensive review of the literature presented in chapter two indicated that teachers in the secondary classroom hold 
misconceptions of both formative assessment and homework which prevents the advancement of classroom assessment. Limited research exists on the use of homework as a formative assessment tool in the secondary classroom. Previous studies used all forms of classroom assessment, with the exception of tests and quizzes, to measure the effectiveness of formative assessment on student achievement (Black et al, 2004; Black \& Wiliam, 1998; Moss \& Brookhart, 2009). The research into homework focused on the impact it had on student achievement, but failed to take into account how homework could be used as a formative assessment tool (Kohn, 2006; Vatterott, 2009).

Many of these previous studies into both formative assessment and homework depended on the conceptual frameworks developed through the lens of all classroom assessment tools. Little attention was given to how educational leaders could assist teachers in the learning process of how to improve current use of formative assessment and specifically homework as a way to improve student achievement. This study's conceptual framework is built upon the concepts of formative assessment and homework as classroom assessment practices aimed at improving student achievement. Additionally, transformational leadership theory and adult learning theory were used as a part of the conceptual framework in order to provide recommendations to educational leaders on how to effect change within their organizations.

\section{Design and Procedures}

Data for this study were collected by conducting interviews and an online, openended survey with public and private school teachers. Interview data was collected by conducting three focus group sessions involving the faculty members of three high schools in 
the Midwest. High schools were selected to represent urban and suburban schools as well as differing student enrollment numbers.

The focus group participants were purposefully selected based on years of experience and content area in which they teach. A focus group interview protocol was developed, but did not bind the interview process. The focus group interview protocol can be found in Appendix A. Online, open-ended surveys provided further interview data and the protocol can be found in Appendix B. Additionally, documents in the form of course syllabi were also analyzed for information about teacher classroom assessment procedures. The document analysis protocol can be found in Appendix C.

The interview and survey results were all interesting and provided rich details. Focus group teachers were reflective and direct in their responses to the questions about their current classroom assessment practice. Many indicated they were using homework as a part of classroom assessment, provided how they use it currently, and were interested in how to improve their practice. A few indicated they had altered their use of homework over their career based on feedback from students. Interestingly, all but a few of the focus group and survey participants stated their current homework and assessment practice was a result of experiences they had as students. Very little professional development had been sought out by participants or provided by their school district professional development programs to assist teachers in gaining new assessment knowledge for application in classroom practice. Overall, the interviews and survey participants gave candid, honest responses which provided data for a rich description of secondary classroom assessment practices in relation to formative assessment and homework. All data were filtered through the theoretical concepts 
of formative assessment as a classroom assessment tool and homework as a classroom assessment tool.

\section{Conclusions Related to the Research Questions}

Within the framework of this study, three research questions were proposed. Witin this section each is addressed with a succinct conclusion from the data.

1. What are teacher assumptions of the purpose of homework as a classroom assessment tool? In relation to this research question, the category of Teacher Perception of the Purpose of Homework emerged from the data analysis. Within this category the following themes emerged and are arranged in order of prevalence; Traditional Practice, Extension of Class Time, Practice, and Student Accountability. The interviews and surveys revealed teachers perceive the use of homework as an extension of learning time and a method to allow students to practice skills. Teacher beliefs of the purpose of homework were described within the theme which emerged from data analysis. Teachers perceived homework as a way to reinforce learned concepts, allow students to finish work not completed in class, and as a method to allow students to explore material outside the class setting. This perception of the purpose of homework is framed by teacher experiences as students, influence of fellow teachers, and a limited number of teachers expressed professional development had increased their knowledge. The wide range of responses to interview and survey questions lead the researcher to conclude that the perception of homework varies greatly among teachers. On more than occasion, teachers expressed their own disillusionment with the purpose of homework within their own classroom. 
2. What are the uses of homework as a part of current classroom assessment practice? In relation to this research question, the category of The Uses of Homework as Part of Classroom Assessment Practice emerged from the data analysis. Within this category the following themes emerged and are arranged in order of prevalence; Checking for Understanding, Grade Balance, and Grade Generation. Interview and survey responses pointed to teachers using homework as a method to check for understanding, a method to hold students accountable for work, a method to allow students to improve their grades, and grade generation. Teachers consistently stated homework allowed them to measure student understanding of key concepts covered during instructional time. More importantly, some teachers viewed homework as guided practice which is a misconception and needs clarification. Teachers also expressed a concern over who might be completing the homework and that students frequently copy each others work. Student accountability was frequently mentioned as a purpose with teachers using homework as a teaching tool with regards to responsibility. Document analysis revealed teachers had punishment measures in place with regards to incomplete homework assignments. Interestingly, teachers used homework as a way to balance student grades versus tests. Several teachers expressed they used homework, in particular completion points, to offset poor test scores.

3. What are current teacher understandings of homework as a formative assessment tool? In relation to this research question, the category of Teacher Understanding of Homework as a Formative Assessment Tool emerged from the data analysis. 
Within this category the following themes emerged and are arranged in order of prevalence; Limited Understanding of Homework as Formative Assessment and Limited Understanding of the Concept of Formative Assessment. The data exposed limited or no understanding of formative assessment as it pertains to homework or any classroom assessment. Teacher responses ranged from those containing some of the key concepts of formative assessment to those which had no idea of the key concepts. The most fascinating aspect of the responses were how teachers understood formative assessment as it pertained to teaching. Answers consistently contained how formative assessment could guide future instruction and assist teachers in modifying lessons. Guiding future instruction is a component of formative assessment, but only a small piece. This idea became apparent from the teachers who did respond they understood formative assessment and points to a lack of professional development in the area of formative assessment.

\section{Discussion}

A review of the existing literature on homework and formative assessment did not appear to directly address teacher perception, use, and understanding of homework as a formative assessment tool. The existing literature on formative assessment has given broad recommendations on how to use formative assessment, but has not addressed specifically how to apply this to homework. The literature on formative assessment provides common teacher misconceptions about the use of formative assessment. The existing literature on homework has addressed the tradition-laden nature of homework and how to dispel these traditions in current practice to make homework a more effective assessment tool. Teacher 
perceptions about the purpose and use of homework and their understanding of formative assessment were found in the data.

Teacher participants consistently stated their current assessment practices were based on their experiences as students, their undergraduate work, and their work with mentor teachers. Existing literature has provided evidence teachers base their assessment practice on the traditional forms of learning expressed above. The nature of classroom assessment is one of deep, longstanding practices embedded in the needs of $20^{\text {th }}$ century society to sort students (Moss \& Brookhart, 2009). Research evidence indicates formative assessment is not currently practiced in the classroom as a result of professional development funding being focused on large national and state assessments (Black \& Wiliam, 1998; Black et al., 2004). All of the teachers noted they had received little or no training in the area of assessment, formative assessment, or homework. These findings support research in the review of literature which points to a lack of funding for large scale professional development for teachers in the area of assessment.

Most teachers had heard of formative assessment, with some having limited knowledge of the concept and how to apply it in the classroom. Over the last decade, many schools have begun to emphasize formative assessment, but the lack of focused professional development has allowed misconceptions to develop in the minds of teachers (Chappius, 2005; Moss \& Brookhart, 2009). This notion is supported in themes which emerged from the data. Teacher respondents consistently stated they had little or no understanding of formative assessment. A common misconception of teachers have of formative assessment is that it is a tool to modify instruction or lesson design, not to improve student learning (Moss \& Brookhart, 2009). Teachers who responded they did have an understanding and were 
applying formative assessment in their classrooms were focused on how assessment could improve their teaching.

Although homework is given to students with the goal of improved learning, not often is this the case (Vatterott, 2009). According to teacher responses, this was one goal of providing homework to students. The themes of Extended Learning Time, Practice, and Checking for Understanding identified from the data demonstrate teachers believe and use homework to improve learning. Furthermore, the sub category of Reading and What Can't be Completed in Class shows teachers believe aspects of learning should take place outside of instructional time as homework. More interestingly, the themes of Student Accountability and Grade Generation emerged from the data both of which can be problematic aspects of homework. Vatterott stated, "Many strategies exist to improve the rate of homework completion, but before discussing those strategies, we must rethink how common practices contribute to the problem" (p. 87).

The common practice of assigning poor grades to incomplete homework or giving completion points, both of which were identified by teachers as strategies, have been shown to have the opposite effect on student motivation. Extrinsic motivation in the form of poor grades or completion points can erode student motivation (Darling-Hammond \& Ifill-Lynch, 2006; Dweck, 2007). Responsibility was a sub category identified in the data. According to recent research merging behavior and learning can create data, in the form of grades, which is not a true measure of student learning (Gathercoal, 2004; O'Connor, 2009). Homework should be utilized by teachers to assist students in obtaining key learning concepts through the use of feedback and improvement toward those key concepts. This was not found in the data and identifies a misuse of homework as it applies to the learning process. Educational 
leaders can help to alter this misconception by providing leadership in the area of professional development.

\section{Implications for Future Practice}

The findings of this study have implications for both teachers and educational administrators. One of the findings of this study clearly shows a misconception on the part of teachers as how homework could be used as formative assessment. The perception of homework as a method to teach student responsibility, improve teaching, and the absence of any responses pertaining to the benefits of formative assessment for students all demonstrate a need for training is this area. Sustained, supported implementation of teaching strategies is the best pathway toward increasing student learning. Unfortunately, the professional development model prevalent across the nation is not sustained or supportive, but rather one shot workshops which have little effect on the classroom (Stiggins, 2002).

To improve student learning, educational leaders need to take a leadership role in the area of organizational learning. Those who are involved day in and day out in the lives of students and teachers can have an influence on classroom practice. Perhaps the most important finding of this study was the apparent need for learning in the area of homework as a formative assessment tool. These findings, coupled with transformational leadership theory and adult learning theory, could impact student learning. Transformational leadership dimensions of providing intellectual stimulation, offering individualized support, and modeling best practices demand school administrators take an active role in providing professional development (Leithwood \& Duke, 1999). Bass (1985) identified the behavior of individualized consideration which involves providing support, coaching, and encouragement of organizational members. Coaching, support, and encouragement are practices school 
leaders can utilize to improve teaching knowledge and application. More importantly, school leaders need to be voracious learners who know about quality teaching, understand and can apply research, and inspire teachers to do the same.

Learning takes place at the center of guided, reflective discourse. The findings of this study demonstrate a need for focused, supported learning in the area of homework as formative assessment. Engaging teachers in dialogue on the critical issues surrounding the current perceptions, uses, and understanding of homework as a classroom assessment tool is necessary for improvement in student learning. For learning to take place, a critical assessment of assumptions supporting current norms is needed (Mezirow, 2000). It is important to build collaborative structures with an emphasis on reframing one's assumptions, and, when this is done, learning can take place. By practicing collaboration, school leaders can change the culture of the educational setting and create a new set of practices. Organizations resistant to change due to the stable structure of existing practice grow increasingly misaligned with the environment in which they operate (Bolman \& Deal, 2003).

The responses to interview and survey questions provide evidence of a system without a cohesive view of how homework should be utilized more effectively in the secondary classroom. Strong leadership, learning as a constant, adherence to research based practice, and collaborative structures could assist educational leaders to affect change in current homework and formative assessment practice. Without such change, homework will continue to be a problematic classroom assessment tool and will fall short of its potential impact on student learning. 


\section{Implications for Future Research}

This study of three Midwestern high schools has identified the perceptions, use, and understanding secondary teachers have of homework as a formative assessment tool. It was an attempt to bring to light the way homework is currently utilized in the secondary classroom and to identify potential ways of making a change to current practice. One of the limits of this study was only teachers in three Midwestern high schools were used in this study. Future research could use a broad sample of teachers across the United States, noting similarities and differences in their perception, use, and understanding of homework as formative assessment in various regions of the country.

Formative assessment concepts as espoused by Chappius (2005), Moss and Brookhart (2009), and Stiggins et al. (2006), proved to be an effective lens through which to view the data. Additionally, research into effective homework practice as described by Kohn (2006) and Vatterott (2009) supported the analysis of data and demonstrated to be an effective lens as well. One area the study did not address which is present in the literature on formative assessment and homework is the type of professional development teachers desire and expect to receive in order to change current practice. This information could demonstrate to be a valuable tool in designing appropriate professional development programming.

It was apparent from the data that teachers have a tradition laden approach to assessment which is embedded in the culture of schools. Potential research in the future could focus on teacher perceptions, use, and understanding of homework before teachers have been engaged in a supportive professional development model. Another suggestion for future research would be to focus on teacher attitudes and practices before and after professional development on homework as formative assessment. Additionally, a focus on 
what it takes to change current teacher practice and the impact on organizational learning could be important in assisting leaders in developing effective professional development plans. As noted in the literature review, support, and coaching are keys to transformational leadership theory and collaboration is a key to organizational learning. Conducting research into teacher implementation and how teachers view educational leaders involved in directly conducting professional development could prove beneficial.

Research has a tendency to focus solely on teachers, with little regard for student opinions. An interesting approach to future research would be to elicit responses from students as to what they have experienced as affective homework assignments. Students often have strong opinions and keen insight into their own educational experiences; it is unfortunate research is limited on their perceptions of homework as a way to further their learning. 


\section{Appendix A}

Teacher Focus Group Interview Protocol

1. Tell me your name, what you teach, and how many years of experience you have in education?

2. What classroom assessments do you currently use?

3. What shaped your current classroom assessment practice?
a. Experience as a student
b. Mentor teachers
c. Professional development
d. Other

4. What are your beliefs of how homework affects student learning?

5. How do you currently use homework as an assessment tool in your classroom?

6. What is your perception of the purpose of homework within the context of classroom assessment?
a. Practice
b. Check for understanding
c. Applying knowledge or skills
d. Grade generation

7. What is the purpose of your current use of homework in classroom assessment practice?
a. Policy driven
b. Student accountability
c. Extension of learning time

8. What is your understanding of formative assessment or assessment for learning?

9. How do you apply formative assessment to homework assignments?

10. Have any of your school professional development programs offered sustained, supported formative assessment?

11. Have any of your school professional development programs offered sustained, supported homework training?

12. I am greatly interested in how to assist teachers in the use of formative assessment in the context of homework. Is there anything you would like to share with me that administrators could do better to help you with the practice of using homework as formative assessment? 


\section{Appendix B}

\section{Online Open-ended Questionnaire}

1. Tell me your name, what you teach, and how many years of experience you have in education?

2. What classroom assessment do you currently use?

3. What shaped your current classroom assessment practice?

4. What are your beliefs of how homework affects student learning?

5. How do you currently use homework as an assessment tool in your classroom?

6. What is your perception of the purpose of homework within the context of classroom assessment?

7. What is the purpose of your current use of homework in classroom assessment practice?

8. What is your understanding of formative assessment or assessment for learning?

9. How do you apply formative assessment to homework assignments?

10. Have any of your school professional development programs offered sustained, supported formative assessment training?

11. Have any of your school professional development programs offered sustained, supported homework training?

12. I am greatly interested in how to assist teachers in the use of formative assessment in the context of homework. Is there anything you would like to share with me that administrators could do better to help you with the practice of using homework as formative assessment? 


\section{Appendix C}

Teacher Syllabi Document Analysis Protocol

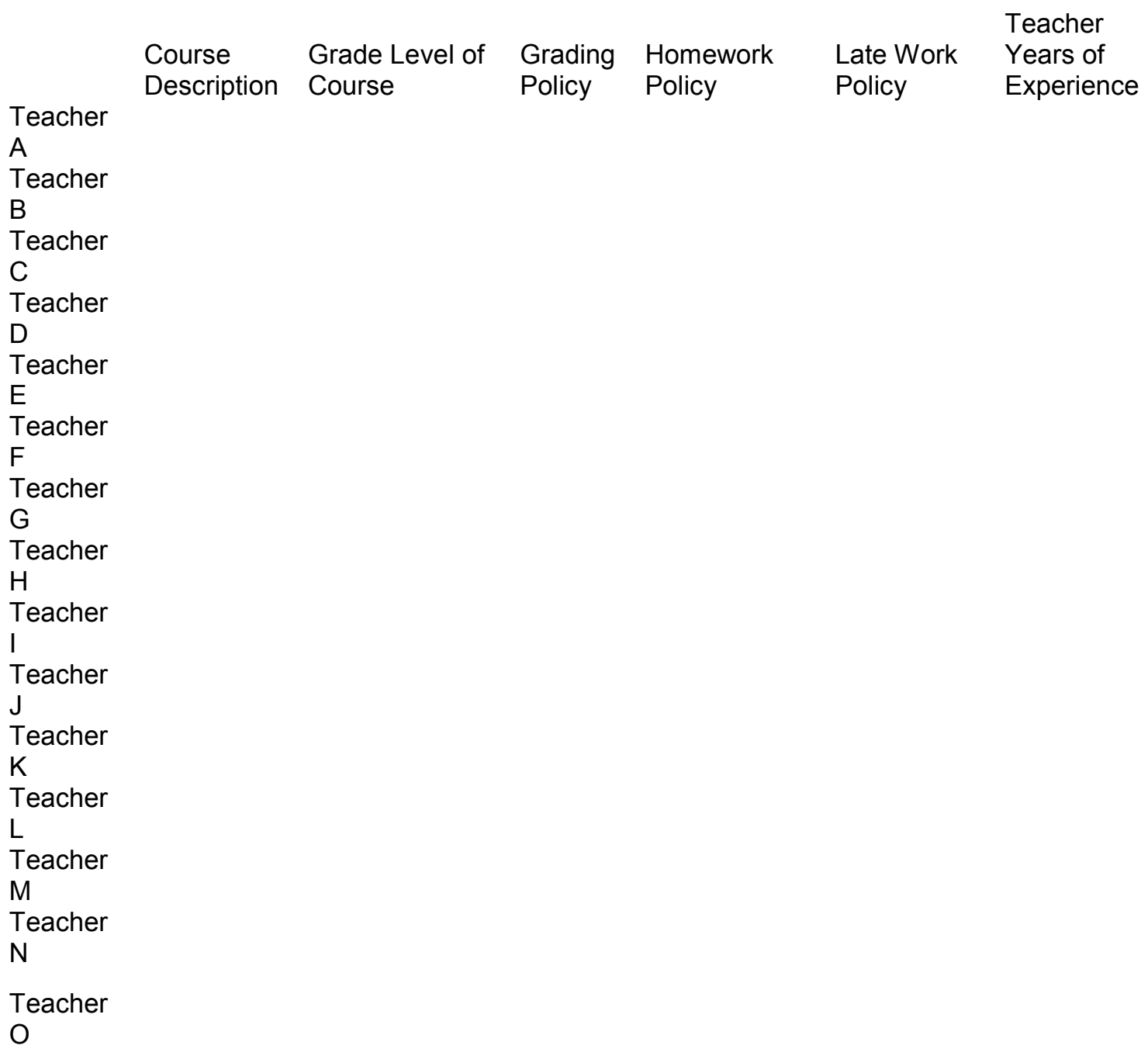




\section{Appendix D}

\section{Informed Consent Online Survey}

\section{Dear Research Participant:}

Thank you for considering participation in the study Understanding Teacher Knowledge of the Use of Assessment for Learning in the Context of Homework. The study is being conducted in partial fulfillment of the requirements for the Doctor of Education degree in Educational Leadership and Policy Analysis at the University of Missouri-Columbia. The purpose of this study is to understand how teachers use homework as an assessment tool in classroom practices. This information will be useful to understand how teachers perceive and use homework as a part of their classroom assessment practices. This research tool is an online survey consisting of twelve open-ended questions.

Before you make a final decision about participation, please read the following about how your input will be used and how your rights as a participant will be protected:

- Participation in the study is completely voluntary. You may stop participating at any point without penalty.

- To the knowledge of the researcher, there are no reasonable and foreseeable risks or discomforts you should experience as a result of participating in this study.

- Your answers will be kept confidential. Results will be presented to others in summary form only without names or other identifying information.

- At the completion of the analysis of the data, all survey results will be deleted from the website.

- Your participation in the online survey will require approximately 30 minutes.

- The data collected will be held in a locked file cabinet in the researchers' offices and disposed of at the conclusion of the study. At your request, we will provide you results of this study.

The Campus Institutional Review Board approved this research study. You may contact the Campus Institutional Review Board if you have questions about your rights, concerns, complaints or comments as a research participant. You can contact the Campus Institutional Review Board directly by telephone or email to voice or solicit any concerns, questions, input or complaints about the research study.

483 McReynolds Hall E-Mail: umcresearchcirb@missouri.edu

Columbia, MO 65211 Website: http:/www.research.missouri.edu/cirb/index.htm

573-882-9585. The project is being supervised by Dr. Robert Watson, Professor, CLSE, Missouri State University (417.836.5177). If at this point you are still interested in participating and assisting with this important research project please fill out the consent form below. Keep this letter for future reference. You can contact Daren Harris at 417.735-3768 if you have questions or concerns about your participation. Thank you very much for your time and consideration.

Sincerely,

Daren Harris

Doctoral Candidate

University of Missouri-Columbia

I, homework as formative assessment. I understand that:

- My answers will be used for educational research.

- My participation is voluntary.

- I may stop participation at any time without penalty.

- I need not answer all of the questions.

- My answers and identity will be kept confidential.

I have read the information above and any questions I asked have been answered to my satisfaction. I agree to participate in this activity, realizing that I may withdraw without prejudice at any time.

Signed:

(optional) For an executive summary of the study's results provide e-mail address: Date: 


\section{Appendix E}

\section{Informed Consent Focus Group Interview}

Dear Research Participant:

Thank you for considering participation in the study Understanding Teacher Knowledge of the Use of Assessment for Learning in the Context of Homework. The study is being conducted in partial fulfillment of the requirements for the Doctor of Education degree in Educational Leadership and Policy Analysis at the University of Missouri-Columbia. The purpose of this study is to understand how teachers use homework as an assessment tool in classroom practices. This information will be useful to understand how teachers perceive and use homework as a part of their classroom assessment practices.

Before you make a final decision about participation, please read the following about how your input will be used and how your rights as a participant will be protected:

- Participation in the study is completely voluntary. You may stop participating at any point without penalty.

- You need not answer all of the questions presented to the group.

- To the knowledge of the researcher, there are no reasonable and foreseeable risks or discomforts you should experience as a result of participating in this study.

- Your answers will be kept confidential; however, confidentiality cannot be guaranteed due to the nature of the focus group data collection procedures. Results will be presented to others in summary form only, without names or other identifying information.

- Your participation will take approximately 90 minutes. During this time you will participate in a focus group interview.

- The data collected will be held in a locked file cabinet in the researchers' offices and disposed of at the conclusion of the study. At your request, we will provide you results of this study.

The Campus Institutional Review Board approved this research study. You may contact the Campus Institutional Review Board if you have questions about your rights, concerns, complaints or comments as a research participant. You can contact the Campus Institutional Review Board directly by telephone or email to voice or solicit any concerns, questions, input or complaints about the research study.

483 McReynolds Hall E-Mail: umcresearchcirb@missouri.edu

Columbia, MO 65211 Website: http://www.research.missouri.edu/cirb/index.htm

573-882-9585 The project is being supervised by Dr. Robert Watson, Professor, CLSE, Missouri State University (417.836.5177). If at this point you are still interested in participating and assisting with this important research project please fill out the consent form below. Keep this letter for future reference. You can contact Daren Harris at 417.735-3768 if you have questions or concerns about your participation. Thank you very much for your time and consideration.

Sincerely,

Daren Harris

Doctoral Candidate

University of Missouri-Columbia

I,

as formative assessment. I understand that:

, agree to participate in the study teacher use of homework

- My answers will be used for educational research.

- My participation is voluntary.

- I may stop participation at any time without penalty.

- I need not answer all of the questions.

- My answers and identity will be kept confidential.

I have read the information above and any questions I asked have been answered to my satisfaction. I agree to participate in this activity, realizing that I may withdraw without prejudice at any time.

Signed: Date:

(optional) For an executive summary of the study's results provide e-mail address: 


\section{Appendix F \\ Focus Group \\ Faculty Invitation Letter}

Thank you for considering participating in my study Understanding Teacher Knowledge of the Use of Assessment for Learning in the Context of Homework. This study is being conducted as part of my dissertation research for my doctoral program in Educational Leadership and Policy Analysis; I am using this study to understand teacher perceptions, knowledge, and use of homework in current classroom assessment practice.

I have been granted permission by the school administration to conduct a focus group at your school. I am seeking approximately 6-8 faculty members who would be willing to participate in a focus group session. Before you make you final decision about participation, please read the following about how your interview will be used and how your rights as a participant will be protected:

Time Involvement: the focus group will take approximately 1 hour to 90 minutes. It will be tape recorded to help facilitate the accuracy of the transcription of the focus group.

To the knowledge of the researcher, there are no reasonable and foreseeable risks or discomforts you should experience as a result of participating in this study. You may decline contributing and participating in the session at any time.

All information you provide will be confidential and grouped with responses from other participants. You will not be identified by name in the findings. If you are interested in receiving a copy of the findings, please contact me by email at daren.harris@republicschools.org

The project has been reviewed and approved by the University of Missouri Campus Institutional Review Board. The committee believes the research procedures adequately safe guards the subject's privacy, welfare, civil liberties, and rights. If you have any questions for the Board, you can contact them at: 483 McReynolds Hall, Columbia, MO. 65211; phone 573-882-9585; email-umcresearchirb@missouri.edu. The project is being supervised by Dr. Robert Watson, Professor, Educational Administration, Missouri State University (417-8365177).

If you would like to participate in this study, please sign and include your contact information, and return this form to your principal. I will call you in approximately one week, to finalize the date and time.

Sincerely, Daren Harris

Name Phone Number 


\section{Appendix G \\ Online Survey \\ Faculty Invitation Letter}

Thank you for considering participating in my study Understanding Teacher Knowledge of the Use of Assessment for Learning in the Context of Homework. This study is being conducted as part of my dissertation research for my doctoral program in Educational Leadership and Policy Analysis; I am using this study to understand teacher perceptions, knowledge, and use of homework in current classroom assessment practice.

I have been granted permission by the school administration to conduct an online survey at your school. Before you make you final decision about participation, please read the following about how your online survey results will be used and how your rights as a participant will be protected:

Time Involvement: the survey will take approximately 30-45 minutes. It will be conducted through Survey Monkey. You will find the link to the survey below. There are two portions to the survey please complete both portions.

To the knowledge of the researcher, there are no reasonable and foreseeable risks or discomforts you should experience as a result of participating in this study. You may decline contributing and participating in the survey at any time.

All information you provide will be confidential and grouped with responses from other participants. You will not be identified by name in the findings. If you are interested in receiving a copy of the findings, please contact me by email at daren.harris@republicschools.org

The project has been reviewed and approved by the University of Missouri Campus Institutional Review Board. The committee believes the research procedures adequately safe guards the subject's privacy, welfare, civil liberties, and rights. If you have any questions for the Board, you can contact them at: 483 McReynolds Hall, Columbia, MO. 65211; phone 573-882-9585; email-umcresearchirb@missouri.edu. The project is being supervised by Dr. Robert Watson, Professor, Educational Administration, Missouri State University (417-8365177).

If you would like to participate in this study, please sign, and return the attached Informed Consent Letter.

Sincerely, Daren Harris 


\title{
Appendix H
}

Transcription Verification E mail

\section{Dear}

Thank you for the time you spent sharing your thoughts and perceptions with me regarding homework as a formative assessment tool.

Attached is the transcript from our interview. Please take some time to read through the transcription. If there are any concerns or inaccuracies, please indicate them on the transcript and return to me.

If you would like a copy of the findings, please let me know, and I will send the results to you.

Thank you for your time, consideration and participation in this study.

\author{
Sincerely, \\ Daren Harris \\ Doctoral Candidate in Educational Leadership and Policy Analysis \\ University of Missouri-Columbia
}




\section{Appendix I \\ Permission to Hold a Focus Group \\ Principal Signature/Approval \\ Informed Consent}

I agree to allow Daren Harris, a doctoral student at the University of Missouri Columbia, to conduct a teacher focus group interview with members of my faculty.

I understand:

The answers will be used in a dissertation study.

Faculty participation is voluntary.

The faculty participants may withdraw at any point during the study.

The individual faculty identity will be protected.

The focus group session will be audio taped and the results of the audio tape will only be reviewed by the researcher.

All data will be kept secure, and then destroyed three years after the completion date of my dissertation.

The focus group sessions will take approximately 60 minutes to 90 minutes.

I have read the information above; my questions have been answered to my satisfaction. I agree to participate in this activity.

Principal Signature:

Date: 


\section{References}

Ames, C. (1992). Classrooms: Goals, structures, and student motivation. Journal of Educational Psychology, 84(3), 261-271.

Barth, R. (1990). Improving schools from within: Teachers, parents and principals can make a difference. San Francisco: Jossey-Bass.

Bass, B. M. (1985). Leadership and performance beyond expectations. New York: Free Press.

Bass, B. M., \& Avolio, B. J. (1990). Developing transformational leadership: 1992 and beyond. Journal of European Industrial Training, 14, 21-27.

Bednarz, D. (1985). Quantity and quality in evaluation research: A divergent view. Evaluation and Program Planning, 8, 289-306.

Black, P., Harrison, C., Lee, C., Marshall, B., \& Wiliam, D. (2004). Working inside the black box: Assessment for learning in the classroom. Phi Delta Kappan, $86(1), 9-21$.

Black, P., \& Wiliam, D. (1998). Inside the black box: Raising standards through classroom assessment. Phi Delta Kappan, 80(2), 139-148.

Bolman, L. G., \& Deal, T. E. (2003). Leadership and management effectiveness: A multi-frame, multi-sector analysis. Human Resource Management, 30, 509-534.

Boston, C. (2002). The concept of formative assessment. College Park, MD: Eric Clearinghouse on Assessment and Evaluation. (Eric Document Reproduction Service No. ED47026, 2002-10-00). Retrieved from: http://www.vtaide.com/png/ ERIC/Formative-Assessment.htm 
Bracey, G. (2009). Big tests: What ends do they serve? Educational Leadership, 67(3), $32-37$.

Brookhart, S. M. (2003). Classroom assessment, student motivation, and achievement in high school social studies classes. Applied Measurement in Education, 16(1), 28.

Brookhart, S. M. (2004). Grading. Upper Saddle River, NJ: Pearson Merrill Prentice Hall.

Brookhart, S. M. (2008). How to give effective feedback to your students. Alexandria, VA: ASCD.

Brown, K. M. (2004). Leadership for social justice and equity: Weaving a transformative Framework and pedagogy. Educational Administration Quarterly, 40, 77-108.

Bruffee, K. A. (1999). Collaborative learning: Higher education, interdependence, and the authority of knowledge (2nd ed.). Baltimore: The Johns Hopkins Press.

Burns, J. M. (1978). Leadership. New York: Harper Colophon Books.

Casey, C. (2006). A knowledge economy and a learning society: A comparative analysis of New Zealand and Australian experiences. Compare, 36(3), 343-357.

Chappius, J. (2005). Helping students understand assessment. Educational Leadership, 63(3), 39-43.

Chappuis, S., Stiggins, R., Arter, J. \& Chappuis, J. (2003). Assessment for learning: An action guide for school leaders. Portland, OR: Assessment Training Institute.

Coghlan, D., \& Brannick, T. (2005). Doing action research in your own organization $\left(2^{\text {nd }}\right.$ ed.). Thousand Oaks, CA: Sage.

College Board. (1998). High school grading policies. Research Notes, RN-04, New York: Author. 
Cooper, H. (2007). The battle over homework: Common ground for administrators, teachers, and parents. ( $3^{\text {rd }}$ ed.) Thousand Oaks: Corwin Press.

Cooper, H., Robinson, J., \& Patall, E. (2006). Does homework improve student achievement? A synthesis of research, 1987-2003. Review of Educational Research, 76(1), 1-62.

Covey, S. (1996). Three roles of the leader in the new paradigm. In F. Hesselbein, M. Goldsmith, \& R. Beckhard (Eds.), The leader of the future (pp. 149-160). San Francisco: Jossey-Bass.

Creswell, J. W. (2003). Research design: Qualitative, quantitative, and mixed methods approaches. Thousand Oaks, CA: Sage.

Creswell, J. W., \& Miller, D. L. (2000). Determining validity in qualitative inquiry. Theory into Practice, 39(3), 124-130.

Cronbach, L. J. (1975). Beyond the two disciplines of scientific physchology. American Psychologist, 30, 116-127.

Crotty, M. (1998). The foundations of social research: Meaning and perspective in the research process. London: Sage.

Darling-Hammond, L. (1999). Teacher quality and student achievement: A review of state policy evidence. Seattle, WA: Center for the Study of Teaching and Policy, University of Washington.

Darling-Hammond, L., \& Ifill-Lynch, O. (2006). If they'd only do their work! Educational Leadership, 63(5), 8-13.

Davis, J. R. (2003). Leaning to lead: A handbook for post secondary administrators, GWestport, CT: American Council on Education and Praeger Publishers. 
Deci, E. L. , Koestner, R., \& Ryan, R. M. (1999). A meta-analytic review of experiments examining the effects of extrinsic rewards on intrinsic motivation. Psychological Bulletin, 125, 627-668.

DuFour, R., \& Eaker, R. (1998). Professional learning communities at work. Bloomington, IN: National Education Service.

Dweck, C. S. (2007). Boosting achievement with messages that motivate. Education Canada, 47(2), 6-10.

Eisner, E. W. (2003-2004). Preparing for today and tomorrow. Educational Leadership, 61(4), 6-11.

Elmore, R. F. (2004). School reform from the inside out: Policy, practice, and performance. Cambridge, MA: Harvard Education Press.

Eraut, M. (2004). Informal learning in the workplace. Studies in Continuing Education, 26(2), 247-273.

Fullan, M. (1993). Change forces: Probing the depths of educational reform. London: Falmer Press.

Gathercoal, F. (2004). Judicious discipline $\left(6^{\text {th }}\right.$ ed). San Francisco: Caddo Gap Press.

Gill, B. P., \& Schlossman, S. L. (2004). Villian or savior? The American discourse on homework, 1850-2003. Theory into Practice, 43(3), 174-181.

Goldberg, K. (2007, April). The homework trap. Paper presented at the annual meeting of the American Educational Research Association, Chicago.

Griffee, D. T. (2005). Research tips: Interview data collection. Journal of Developmental Education, 28(3), 36-47. 
Guskey, T. R. (2004a, April). Stability and change in high school grades. Paper presented at the annual meeting of the American Educational Research Association, San Diego.

Guskey, T. R. (2004b). Are zeroes your ultimate weapon. Principal Leadership, 60(5), 49-53.

Guskey, T. R. (2009). Practical solutions for serious problems in standards-based grading. Thousand Oaks, CA: Corwin Press.

Guskey, T. R., \& Anderman, E. M. (2008). Students at bat. Educational Leadership, 66(3), $8-14$.

Guskey, T. R., \& Bailey, J. M. (2001). Developing grading and reporting systems for student learning. Thousand Oaks, CA: Corwin Press.

Hanushek, E. A., Kain, J. F., O’Brien, D. M., \& Rivkin, S. G. (2005). The market for teacher quality. (NBER Working Paper 11154). Washington, DC: National Bureau of Economic Research.

Herr, K., \& Anderson, G. L. (2005). The action research dissertation: A guide for students and faculty. Thousand Oaks, CA: Sage.

Institute for Management Development. (2009). World competitiveness yearbook. Lausanne, Switzerland: Author.

Johnson, Jr., J. H., \& Kasarda, J. D. (2008). Jobs on the Move: Implications for U.S. higher education. Planning for Higher Education, 36(3), 22-33.

Kasl, E., Marsick, V., \& Dechant, K. (1997). Teams as learners. Journal of Applied Behavioral Science, 33(2), 227-246. 
Kohn, A. (1999). Punished by rewards: The trouble with gold stars, incentive plans, and $A$ 's, praise, and other bribes ( $2^{\text {nd }}$ ed.). New York: Houghlin Mifflin.

Kohn, A. (2006). The homework myth: Why our kids get too much of a bad thing. Cambridge, MA: Da Capo Press.

Krueger, R. A., \& Casey, M. A. (2000). Focus group: A practical guide for applied research. New York: The Free Press.

Lagemann, E. C. (2007). Public rhetoric, public responsibility, and the public schools. Education Week, 26(37), 29, 30.

Leithwood, K., \& Duke, D. L. (1999). A century's quest to understand school leadership, (pp. 45-72). In J. Murphy \& K. Seashore-Louis Handbook of Research on Educational Administration. San Francisco: Jossey-Bass.

Leithwood, K., Jantzi, D., \& Steinbach, R. (2000). Changing leadership for changing times. Philadelphia: Open University Press.

Lincoln, Y. S. (1995). Emerging criteria for quality in qualitative and interpretive research. Qualitative Inquiry, 1(1), 275-289.

Marzano, R. J., Pickering, D., \& Pollack, J. E. (2001). Classroom instruction that works: Research based strategies for increasing student achievement. Alexandria, VA: ASCD.

McMillan, J. H. (2001). Secondary teachers classroom assessment and grading practices. Educational Measurement; Issues and Practices, 20(1), 20-32.

Merriam, S. B. (1998). Qualitative research and case study applications in education. San Francisco: Josey-Bass. 
Mezirow, J., (with Associates). (2000). Learning as transformation. San Francisco: JosseyBass.

McNeil, D., \& Frieberger, P. (1993). Fuzzy logic: The discovery of revolutionary computer technology and how it is changing our world. New York: Simon \& Schuster.

Morgan, G. (2006). Images of organization. Thousand Oaks, CA: Sage.

Moss, C. (2002). Professional learning on the cyber sea: What is the point of contact? In R. Hall (Ed.), Special Topic Issue: World Wide Web and Education, Journal of of Cyberpsychology and Behavior, 1(3), 41-50.

Moss, C., \& Brookhart, S. (2009). Advancing formative assessment in every classroom: A guide for instructional leaders. Alexandria, VA: ASCD.

Moustakas, C. (1994). Phenomenological research methods. Thousand Oaks, CA: Sage. National Commission on Excellence in Education. (1983). A nation at risk. Washington, DC: U.S. Government Publishing Office.

Nonaka, I. (1991). The knowledge-creating company. Harvard Business Review, 85(7/8), $162-171$.

Nonaka, I. (1994). A dynamic theory of organizational knowledge creation. Organizational Science, 5(1), 14-37.

O’Connor, K. (2002). How to grade for learning: Linking grades to standards. Thousand Oaks, CA: Corwin Press.

O’Connor, K. (2009). Reforming grading practices in secondary schools. Principal's Research Review, 4(1), 1-7. 
Patton, M. Q. (1990). Qualitative evaluation methods. ( $2^{\text {nd }}$ ed.). Thousand Oaks, CA: Sage.

Patton, M. L. (2007). Understanding research methods: An overview of the essentials. Glendale, CA: Pyrczak.

Polanyi, M. (1966). The tacit dimension. London: Routledge \& Kegan Paul.

Popham, W. J. (2003) Test better, teach better: The instructional role of assessment. Alexandria, VA: ASCD.

Porter, M. E., \& Schwab, K. (2008). The global competitiveness report 2008-2009. Geneva, Switzerland: World Economic Forum.

Quevedo, S. (2007). Spellings report targets higher education. The ASHA Leader, 12(5), 1, 12.

Reeves, D. B. (2008). Effective grading practices. Educational Leadership, 65 (5), 85-87.

Resnick, J. (2006). International organizations, the "education-economic growth" black box, and the development of world education culture. Comparative Education Review, 50(2), 173-195.

Rossman, G. B., \& Rallis, S. F. (1998). Learning in the field: An introduction to qualitative research. Thousand Oaks, CA: Sage.

Sagor, R. (2002). Lessons from skateboarders. Educational Leadership, 60 (1), 34-38.

Sagor, R. (2008). Cultivating optimism in the classroom. Educational Leadership, 65 (6), 26-31. 
Schein, E. H. (1992). Organizational culture and leadership (2 $2^{\text {nd }}$ ed.). San Francisco, CA: Jossey-Bass.

Schreiber, J. B., Moss, C. M., \& Staab, J. (2007). A preliminary examining of a theoretical model for researching educator beliefs. Semiotica, 164, 153-172.

Seidman, I. (1998). Interviewing as qualitative research: A guide for researchers in education and the social sciences ( $2^{\text {nd }}$ ed.). New York: Teachers College Press.

Shields, C. M. (2004). Dialogic leadership for social justice: Overcoming pathologies of silence. Educational Administration Quarterly, 40, 109-132.

Sternberg, R. J. (2006, February, 22). Creativity is a habit (Commentary). Education Week, p. 47.

Stiggins, R. J. (2002). Assessment crisis: The absence of assessment for learning. Phi Delta Kappan, 83(10), 758-765.

Stiggins, R. J. (2004). New assessment beliefs for a new school mission. Phi Delta Kappan, 86(1), 22-27.

Stiggins, R. J. (2008). Assessment manifesto: A call for the development of balanced assessment systems. Retrieved from: www.ets.org/ati.

Stiggins, R. J., Arter, J., Chappius, J., \& Chappius, S. (2006). Classroom assessment for student learning: Doing it right-using it well. Portland, OR: ETS.

Taylor, F. W. (1911). The principles of scientific management. New York: Harper $\&$ Brothers.

Thompson, M., \& Wiliam, D. (2007, October). Tight but loose: A conceptual framework for scaling up school reform. Paper presented at the annual meeting of the American Educational Research Association, Chicago. 
Thoreau, H. D. (1854). Walden. Reprinted in 2005. New York: Barnes and Noble.

Tomlinson, C. (2003). Deciding to teach them all. Educational Leadership, 61

(2), 7-11.

Trautwein, U., \& Koller, O. (2003). The relationship between homework and achievement, still much of a mystery. Educational Psychology Review, 15(2), $115-145$

Vatterott, C. (2009). Rethinking homework: Best practices that support diverse needs Alexandria, VA: ASCD.

Vatterott, C. (2010). Five hallmarks of good homework. Educational Leadership, 68(1), 10 15

Vispoel, W. P., \& Austin, J. R. (1995). Success and failure in junior high school: A critical incident approach to understanding students' attributional beliefs. American Educational Research Journal, 32(2), 377-412.

Wildman, P. R. (1968). Homework pressures. Peabody Journal of Education, 45(4), 204.

Wilkinson, G. (2006). McSchools for McWorld? Mediating global pressures with a mcdonaldizing education policy response. Cambridge Journal of Education. $36(1), 81-98$.

Yorke, M., \& Knight, P. T. (2006). Curricula for economic and social gain. Higher Education. 51(4), 565-588.

Yukl, G. (2006). Leadership in organizations. Patapargnanj, India: Dorling Kindersley.

Zakaria, F. (2006, January 9). We all have a lot to learn. Newsweek. Retrieved from: www. fareedzakaria.com/ARTICLES/newsweek/010906.html 


\section{VITA}

Daren Harris was born September 29, 1966, in Springfield, Missouri. He attended all 13 years of public school in Republic, Missouri. After graduation from high school Daren received the following degrees: BS in Physical Education and Secondary Education from Southwest Missouri State University (1989); MS in Secondary Education from Drury University (1997), and; Ed.D in Educational Leadership and Policy Analysis from the University of Missouri-Columbia (2011). Mr. Harris has been in the business of education for all of his adult life. He is currently the principal of Republic High School in Republic, Missouri. 